\title{
Plan for the Testing of Radiation Measurement Instrumentation Intended for Use at an Excavation Site
}

Robert J. Gehrke

Published November 1994

Idaho National Engineering Laboratory Lockheed Idaho Technologies Company Idaho Falls, Idaho 83415

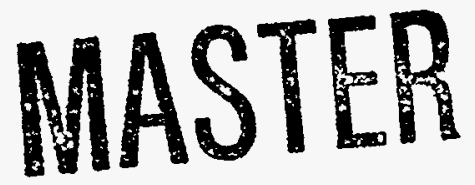

Prepared for the

U.S. Department of Energy

Assistant Secretary for Environmental Management Under DOE Idaho Operations Office

Contract DE-AC07-94ID13223 


\section{DISCLAIMER}

This report was prepared as an account of work sponsored by an agency of the United States Government. Neither the United States Government nor any agency thereof, nor any of their employees, make any warranty, express or implied, or assumes any legal liability or responsibility for the accuracy, completeness, or usefulness of any information, apparatus, product, or process disclosed, or represents that its use would not infringe privately owned rights. Reference herein to any specific commercial product, process, or service by trade name, trademark, manufacturer, or otherwise does not necessarily constitute or imply its endorsement, recommendation, or favoring by the United States Government or any agency thereof. The views and opinions of authors expressed herein do not necessarily state or reflect those of the United States Government or any agency thereof. 


\section{DISCLAIMER}

Portions of this document may be illegible in electronic image products. Images are produced from the best available original document. 
Plan for the Testing of Radiation Measurement Instrumentation Intended for Use at an Excavation Site

Prepared by

Pallet gifluhe

$$
\frac{\text { Nov } 9,1994}{\text { Date }}
$$

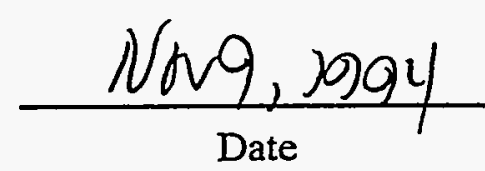

Date

Approved by

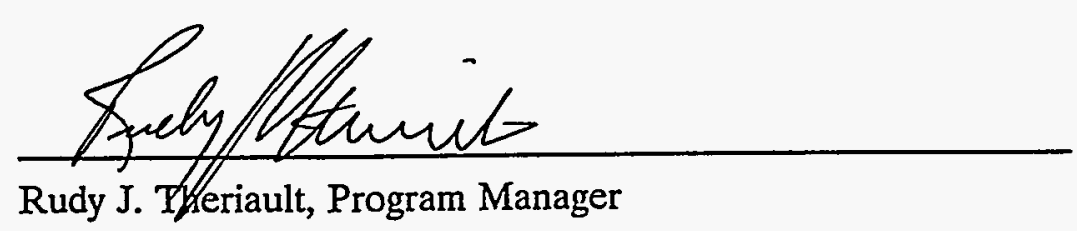

Rudy J. Theriault, Program Manager $\frac{\text { No69.1994 }}{\text { Date }}$ 


\begin{abstract}
This plan describes performance tests to be made with ionizing radiation measurement instrumentation designed and built for in-field assay at an excavation site. One instrument measures gross gamma-ray and neutron fields and the other identifies gamma-ray emitting radionuclides and also is capable of assaying for selected hazardous materials. These instruments will be operationally tested to verify that original specifications have been met and performance tested to establish and verify that they have the potential to function as intended at an excavation site.
\end{abstract}




\section{SUMMARY}

This plan describes objectives, instrumentation, and performance tests for ionizing radiation instrumentation that will be used at an excavation site. This instrumentation is being developed under the digface characterization project. The purpose of the digface characterization technology is to provide sensing capability that allows an adaptive approach to buried waste remediation. The use of characterization at the digface will ultimately reduce environmental, health, and safety risks during cleanup of buried waste sites as supported by published system design studies. The requirement for characterization at the digface results from the inability of current characterization technologies to provide sufficient location and characterization information when deployed from ground surface prior to the start of remediation operation. However, these same approaches, when deployed continuously during retrieval, may provide the information needed to meet production, operational, and safety needs.

An adaptive approach performs cleanup in small steps by alternately characterizing and then digging safe increments of the subsurface. The requirements for characterization within such a system are different than for conventional waste site remediation. Characterization is required only for a thin zone in the immediate subsurface of the digface. The digface monitoring technology that performs this function must be highly effective at screening this shallow zone for hazards, which can then be removed by cleanup equipment. The digface sensors provide constant surveillance and screening as hazards are gradually exposed by the cleanup operation. As cleanup proceeds, hazards are monitored from progressively closer viewpoints until complex features of the waste are resolved. This is the key technical advantage to the digface monitoring technology.

The Buried Waste Integrated Demonstration (BWID) characterization study was started in 1992 with the preparation of a conceptual design. Substantial development activities were initiated in 1993, and there are currently three main project subtasks: (1) demonstration of concept feasibility and development of data interpretation concepts, (2) development of robotics deployment capability, and (3) development of prototype sensors for application at the digface.

Digface characterization is only one unit of a complex remediation system. Therefore, support must be assumed from mobile laboratories as well as U.S. Environmental Protection Agency-certified laboratories. It is anticipated the digface system will only be providing screening level data. This is consistent with the safety primacy of the system. Analyses that are required to certify clean versus unclean soil are not expected to be made with a digface characterization system. If appropriate from a system point of view, the digface system could provide information for educated guesses that would require subsequent verification.

This plan describes performance tests to be made with ionizing radiation measurement instrumentation designed and built for in-field assay. One instrument measures gross gamma-ray and neutron fields and the other identifies gamma-ray emitting radionuclides and also is capable of assaying for selected hazardous materials. These instruments will be operationally tested to verify that original specifications have been met and performance tested to establish and verify that they have the potential to function at an excavation site. 


\section{CONTENTS}

ABSTRACT $\ldots \ldots \ldots \ldots \ldots \ldots \ldots \ldots \ldots \ldots \ldots \ldots \ldots \ldots \ldots \ldots \ldots \ldots \ldots \ldots \ldots \ldots$

SUMMARY $\ldots \ldots \ldots \ldots \ldots \ldots \ldots \ldots \ldots \ldots \ldots \ldots \ldots \ldots \ldots \ldots \ldots \ldots \ldots$

CONTENTS $\ldots \ldots \ldots \ldots \ldots \ldots \ldots \ldots \ldots \ldots \ldots \ldots \ldots \ldots \ldots \ldots \ldots \ldots \ldots \ldots$ vii

ACRONYMS $\ldots \ldots \ldots \ldots \ldots \ldots \ldots \ldots \ldots \ldots \ldots \ldots \ldots \ldots \ldots \ldots \ldots \ldots \ldots \ldots$ ix

1. INTRODUCTION $\ldots \ldots \ldots \ldots \ldots \ldots \ldots \ldots \ldots \ldots \ldots \ldots \ldots \ldots \ldots \ldots \ldots \ldots$

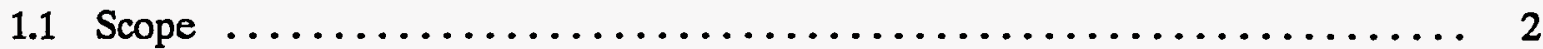

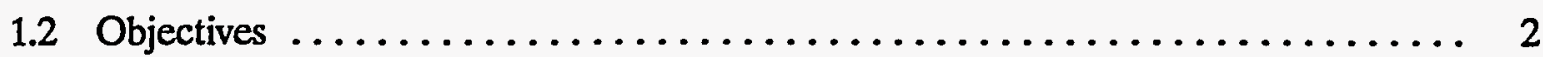

1.3 Technology Agreement $\ldots \ldots \ldots \ldots \ldots \ldots \ldots \ldots \ldots \ldots \ldots \ldots \ldots \ldots \ldots$

1.4 Customer Need $\ldots \ldots \ldots \ldots \ldots \ldots \ldots \ldots \ldots \ldots \ldots \ldots \ldots \ldots \ldots \ldots \ldots$

2. ORGANIZATION AND RESPONSIBILITIES $\ldots \ldots \ldots \ldots \ldots \ldots \ldots \ldots \ldots \ldots$

2.1 Personnel Responsibilities $\ldots \ldots \ldots \ldots \ldots \ldots \ldots \ldots \ldots \ldots \ldots \ldots \ldots \ldots \ldots \ldots$

2.2 Personnel Support Requirements $\ldots \ldots \ldots \ldots \ldots \ldots \ldots \ldots \ldots \ldots \ldots \ldots \ldots \ldots$

2.3 Monitoring and Surveillance $\ldots \ldots \ldots \ldots \ldots \ldots \ldots \ldots \ldots \ldots \ldots \ldots \ldots$

3. DESCRIPTION OF TESTS $\ldots \ldots \ldots \ldots \ldots \ldots \ldots \ldots \ldots \ldots \ldots \ldots \ldots \ldots$

3.1 Test of the Gamma-Ray/Neutron Monitor $\ldots \ldots \ldots \ldots \ldots \ldots \ldots$

3.1.1 System Tests $\ldots \ldots \ldots \ldots \ldots \ldots \ldots \ldots \ldots \ldots \ldots \ldots \ldots \ldots$

3.1.2 Gamma Detector Tests $\ldots \ldots \ldots \ldots \ldots \ldots \ldots \ldots \ldots \ldots \ldots \ldots$

3.1.3 Neutron Detector Tests $\ldots \ldots \ldots \ldots \ldots \ldots \ldots \ldots \ldots \ldots \ldots \ldots \ldots$

3.2 Test of the Gamma-Ray Spectrometer $\ldots \ldots \ldots \ldots \ldots \ldots \ldots \ldots \ldots \ldots \ldots$

3.2.1 Installation of Gamma-Ray Spectrometer $\ldots \ldots \ldots \ldots \ldots \ldots \ldots \ldots \ldots$

3.2.2 Automatic Energy Calibration with Dual-Energy Pulser . . . . . . . . 12

3.2.3 Suitability of One Gain to Cover Entire Energy Range of Ge Spectrometer . . . . . . . . . . . . . . . . . . . 13

3.3 PGNAA Measurements with the Gamma-Ray Spectrometer $\ldots \ldots \ldots \ldots \ldots$

3.3.1 PGNAA Measurements $\ldots \ldots \ldots \ldots \ldots \ldots \ldots \ldots \ldots \ldots \ldots \ldots \ldots \ldots$ 
4. SEQUENCE OF ACTIVITIES $\ldots \ldots \ldots \ldots \ldots \ldots \ldots \ldots \ldots \ldots \ldots \ldots \ldots \ldots \ldots \ldots \ldots \ldots \ldots$

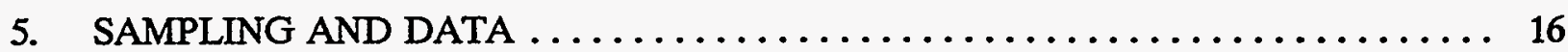

6. DOCUMENT CONTROL $\ldots \ldots \ldots \ldots \ldots \ldots \ldots \ldots \ldots \ldots \ldots \ldots \ldots \ldots \ldots \ldots \ldots \ldots \ldots \ldots$

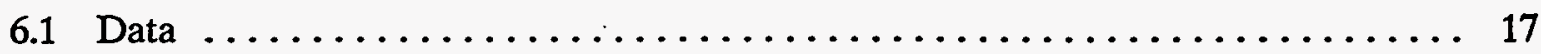

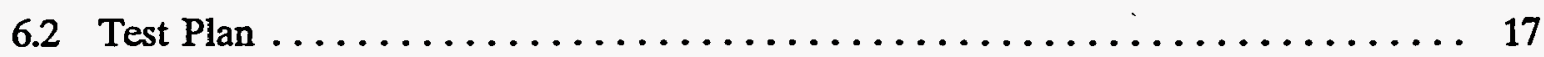

7. ANALYTICAL METHODS $\ldots \ldots \ldots \ldots \ldots \ldots \ldots \ldots \ldots \ldots \ldots \ldots \ldots \ldots \ldots \ldots \ldots \ldots$

8. DATA REDUCTION, VALIDATION, AND VERIFICATION ............. 19

8.1 Data Quality Objectives $\ldots \ldots \ldots \ldots \ldots \ldots \ldots \ldots \ldots \ldots \ldots \ldots \ldots \ldots$

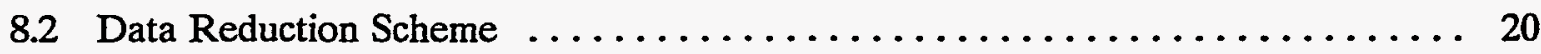

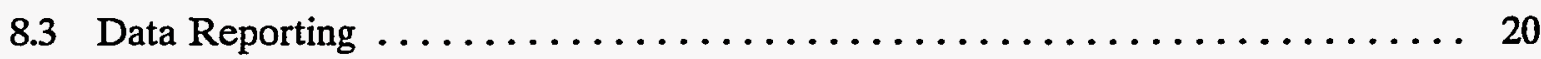

9. QUALITY ASSURANCE $\ldots \ldots \ldots \ldots \ldots \ldots \ldots \ldots \ldots \ldots \ldots \ldots \ldots \ldots \ldots \ldots \ldots \ldots \ldots$

10. EQUIPMENT AND INSTRUMENTS $\ldots \ldots \ldots \ldots \ldots \ldots \ldots \ldots \ldots \ldots \ldots \ldots \ldots \ldots \ldots \ldots \ldots$

11. SUPPLIES, UTILITIES, AND FACILITIES $\ldots \ldots \ldots \ldots \ldots \ldots \ldots \ldots \ldots \ldots$

12. HEALTH AND SAFETY $\ldots \ldots \ldots \ldots \ldots \ldots \ldots \ldots \ldots \ldots \ldots \ldots \ldots \ldots \ldots \ldots \ldots$

13. RESIDUALS MANAGEMENT $\ldots \ldots \ldots \ldots \ldots \ldots \ldots \ldots \ldots \ldots \ldots \ldots \ldots \ldots \ldots \ldots \ldots \ldots$

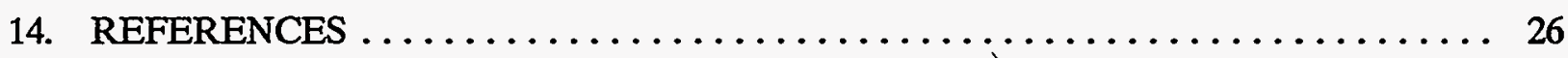

Appendix A - Conceptual Drawings Showing Use of Sensors at an Excavation Site ...... A-1

Appendix B - Specifications in Request for Proposal for Gamma/Neutron Radiation

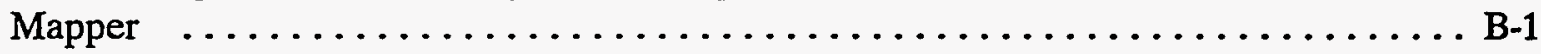

Appendix C - Chapters 2 and 5 of GNM-620 Operating and Service Manual

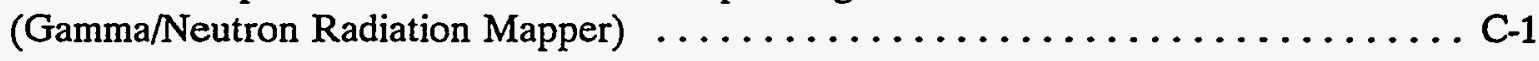

Appendix D - Documentation for NEPA Categorical Exclusion (CX) for Radiation Measurements Laboratory at Test Reactor Area $\ldots \ldots \ldots \ldots \ldots \ldots \ldots \ldots \ldots$ D-1 


\section{ACRONYMS}

\begin{tabular}{ll} 
BWID & Buried Waste Integrated Demonstration \\
CERCLA & Comprehensive Environmental Response, Compensation, and Liability Act \\
FQO & data quality objective \\
INEL & fiscal year \\
N\&RP & Idaho National Engineering Laboratory \\
OTD & Office of Technology Development \\
PGNAA & prompt gamma neutron activation analysis \\
PI & principal investigator \\
PINS & Portable Isotopic Neutron Spectroscopy \\
PVC & polyvinyl chloride \\
RFP & Request For Proposal \\
RM\&D & Radiation Measurements and Development Unit \\
TRA & Test Reactor Area \\
TS & Technical Specification \\
\hline
\end{tabular}




\section{Plan for the Testing of Radiation Measurement Instrumentation Intended for Use at an Excavation Site}

\section{INTRODUCTION}

The Buried Waste Integrated Demonstration (BWID) characterization study was started in 1992 with the preparation of a conceptual design. ${ }^{1,2}$ Substantial development activities were initiated in 1993 and there are currently three main project subtasks: (1) demonstration of conceptual feasibility and development of data interpretation concepts, (2) development of robotics sensor deployment capability, and (3) development of prototype sensors for application at the digface.

The prompt gamma neutron activation analysis (PGNAA) task was initiated midway through FY-93 resulting in initial measurements that demonstrated the ability to detect chlorine mixed with soil, stainless steel scrap, and lead located inside 55-gal drums. In addition to these measurements, measurements were also made on surrogate and actual transuranic waste in 55-gal drums in the TRUPACT building at the Stored Waste Experimental Pilot Plant ${ }^{3}$ with a Portable Isotopic Neutron Spectroscopy (PINS) system developed with funding from the Office of Research and Development (NN20).

Based on the experience gained in FY-93, three characterization systems were proposed for development in FY-94 under this task. Appendix A provides conceptual drawings of the sensors to be attached to the trolley or gantry crane for systematic characterization at an excavation site. These characterization systems, which were designed to characterize the neutron and gamma-ray radiation fields and the presence of potentially hazardous materials in the overburden, sideburden and material present in the burial site proper, consist of (a) a neutron/gamma radiation mapper to measure the neutron and gamma radiation fields, (b) a Ge spectrometer for radionuclide identification, and (c) a PGNAA system for identification of key elements associated with hazardous materials. The latter system will be used primarily to identify potential plumes of chlorinated organics or containers with chlorinated organics.

This plan, based on BWID guidance, ${ }^{4}$ describes performance tests to be made with the measurement instrumentation described above and designed and built for in-field assay at an excavation site. One instrument measures gross gamma-ray and neutron fields and the other identifies gamma-ray emitting radionuclides and also is capable of assaying for selected hazardous materials. These instruments will be operationally tested to verify that original specifications have been met and performance tested to establish and verify that they have the potential to function at an excavation site. This plan describes tests for two separate instruments used to perform three separate kinds of measurements.

The first instrument to be tested consists of a gamma-ray/neutron radiation monitor for rapid scanning of a digface for the purpose of mapping the gamma-ray and neutron radiation fields as a function of location and for the identification of radioactive hot spots. The instrument consists of two identical neutron chambers with a $\mathrm{He}-3$ detector located within each chamber. The direction 
of the chambers facing the excavation are each covered by a plastic scintillator of the same size as the neutron chamber. Analog signals from each $\mathrm{He}-3$ and each plastic scintillator are read out as a function of time to provide a mapping of the gamma-ray and neutron radiation fields as a function of location.

The second instrument is a Ge gamma-ray spectrometer for use at the excavation site in the identification of the radionuclides present. This spectrometer is equipped with a dual-energy pulser for automatic energy calibration of every gamma-ray spectrum. The pulser also provides correction for pulse pile-up and monitors the noise and energy resolution of the spectrometer. This instrument with the addition of a Cf- 252 source, reflector/moderator block, and active or passive shadow shielding can also be used to perform PGNAA at the excavation site.

\subsection{Scope}

The scope of this test is limited to laboratory evaluations of basic performance of radio analytical instruments (and associated software) being developed for use at an excavation site. These tests are being performed independent of other digface characterization tests being performed in FY-94. Weekly progress will be communicated to the principal investigator, N. E. Josten, who has overall responsibility for the digface characterization work.

\subsection{Objectives}

The objective of this plan is to perform a series of measurements to test the operation and performance of the gamma-ray/neutron radiation monitor and the gamma-ray spectrometer. A set of measurements will be performed for each type of measurement as described in Section 3, "Description of Tests." Whenever a specific parameter is to be measured, it shall be measured to an accuracy of at least $\pm 25 \%$ (whenever higher accuracy is required from a performance test, it shall be specified). Specific objectives for the gamma-ray/neutron radiation monitor are:

- To verify that all specifications listed in the requisition have been met and to document those specifications that have not been met

- To measure the performance characteristics of the gamma-ray/neutron radiation monitor.

Specific objectives for the gamma-ray spectrometer as used to measure radionuclides present are:

- To verify that the Ge detector and pulse-processing electronics including the dualenergy pulser will operate as intended

- To verify that all associated software for control and analysis are functional

- To measure the performance characteristics of the Ge spectrometer. 
The specific objective for the gamma-ray spectrometer as used to perform prompt gamma/neutron activation at the digface is to measure the PGNAA sensitivity for chlorine as a function of soil depth for the Cf-252/Ge spectrometer system.

\subsection{Technology Agreement}

The Nuclear and Radiological Physics (N\&RP) and Radiation Measurements and Development units of EG\&G Idaho, Inc., participate in the BWID program to develop a digface characterization system that will provide mapping of ionizing radiation, identification and assay of the radionuclide inventory, and assay of certain key hazardous elements at an excavation site by PGNAA. This project is a continuation of the FY-93 Technical Task Plan ID-132003, "Digface Characterization," and covers work needed to prepare the digface characterization system for use at an excavation site.

\subsection{Customer Need}

The instruments being developed for the digface characterization project are necessary to ensure the safe removal of radioactive and mixed waste from an excavation site. 


\section{ORGANIZATION AND RESPONSIBILITIES}

This work is sponsored by the Office of Technology Development (OTD) through the BWID program at the Idaho National Engineering Laboratory (INEL) for the purpose of developing radiation measuring instrumentation. The organizational affiliations and responsibilities of the key personnel involved in the development and testing of the radiation measuring instrumentation for use at an excavation site are listed below in Section 2.1. Personnel from the N\&RP and RM\&D units of EG\&G Idaho will perform all measurements.

\subsection{Personnel Responsibilities}

Nicholas E. Josten, the primary principal investigator (PI), will be responsible for the overall technical management of the project. He will also direct the field testing and the data analysis activities during and after the field tests.

Robert J. Gehrke, PI, will be responsible for the overall scientific development of the radiation instrumentation to be used at an excavation site. He will be also responsible for carrying out the performance tests on the gamma-ray spectrometer. He has 29 years experience in basic and applied research in the areas of x-ray and gamma-ray spectrometry with over 60 journal publications.

Robert S. Lawrence, PI, will be responsible for carrying out the performance tests on the gamma/neutron monitor and for setting up the gamma-ray spectrometer. He has over 35 years experience in the design, building, testing, and maintenance of electronic circuits and their control including that for fast pulse circuitry. Lawrence is the technical leader of the electronics personnel in the RM\&D Unit.

E. Wayne Killian, PI, will be responsible for the development of the software that has been and may need to be developed for control and analysis of data taken with the gamma-ray spectrometer. Specifically, he has developed the VAXGAP family of programs that control the analyzer, calibrate the spectra, and analyze the dual-energy pulser data.

Gehrke and Lawrence also will be responsible for carrying out this test plan. Any other individuals who participate in making measurements in support of this test plan shall be under the direct supervision of either Gehrke or Lawrence. All personnel making measurements shall be radiation workers working under a Radioactive Work Permit. Support from Health Physics personnel will be specified in the Radioactive Work Permit. Josten, the primary PI, will inspect the test plan activities and associated documentation at least once during the test.

\subsection{Personnel Support Requirements}

All experimental work will be performed by the PIs, or by personnel from the RM\&D and N\&RP units of EG\&G Idaho who are functioning under the direction of the PIs. These staff are senior-level, technically degreed scientists and engineers with experience in radiation instrumentation and in the measurement of ionizing radiation. Interface with other units will be through Josten, the PI with overall responsibility for the digface project. Experiments will be 
performed at the Test Reactor Area (TRA). Selected sites for demonstration of the instruments and equipment associated with the digface project will be evaluated in a subsequent test plan.

\subsection{Monitoring and Surveillance}

Monitoring of measurement activities will be provided by program project management through Josten, the primary PI. Monitoring will be performed at the RM\&D facility as required by the PI or by independent sources designated by the PI. 


\section{DESCRIPTION OF TESTS}

These tests are designed to verify basic operational and performance characteristics for the intended use of this equipment at an excavation site. Appendix A, Sections 3.2, 3.3, 3.6, and 3.8 of the Buried Waste Integrated Demonstration Technology Test Plan Guidance ${ }^{3}$ are addressed below.

The tests to be conducted are described in detail in Sections 3.1, 3.2, and 3.3. If quality data are acquired, tests will not be repeated. Any individual test will be repeated if the measured data are of questionable quality as determined by the PI in charge of the test. These tests will be conducted in the physics or electronics laboratories at TRA and shall be completed prior to the end of FY-94. All equipment is available. No contingency plan will be made. Any tests that cannot be carried out due to major deficiencies in the equipment will be documented. These tests will evaluate the capability to carry out characterizations at the digface of an excavation site to provide a margin of safety to the excavation personnel. Uncertainty requirements will be judged individually by the PI in charge of the test. When not specified by the test plan, measurement uncertainties should be equal to or less than $\pm 25 \%$ (one standard deviation).

Table 1 lists the full-scale operation estimates based upon present brief experience with the equipment.

\subsection{Test of the Gamma-Ray/Neutron Monitor}

The tests for the gamma-ray/neutron monitor are divided into three primary sections. These are: (1) system tests (these tests check the properties of the system that are common to both the gamma-ray and neutron detector sections of the system and include procedures that are outlined in the vendor's Operating and Service Manual (the pertinent sections are attached in Appendix B) for the gamma-ray/neutron monitor), (2) gamma detector tests (these tests check the properties of the system that are peculiar to the gamma detector portion of the system), and (3) neutron detector tests (these tests check the properties of the neutron detector portion of the system). Each of these primary sections are subdivided into two subsections. The subsections are: (1) acceptance tests to verify the system meets the technical specifications (TS) required in the Request For Proposal (RFP) (specifications reprinted in Appendix B) and (2) additional characterization tests not required in the RFP. Data from these tests will subsequently be used to develop calibration procedures and to determine if any system modifications are required to optimize the system for the specific application at the INEL. The results of all tests shall be recorded in a formal logbook.

Perform the setup and calibration procedures outlined in Sections 2 (Inspection and Setup) and 5 (Maintenance) of the vendor's Operating and Service Manual prior to the following sections of this test plan: systems, gamma detector, and neutron detector tests. Sections 2 and 5 of the vendor's Operating and Service Manual are attached to this plan as Appendix C. 
Table 1. Full-scale operation estimates.

a

b

c

d

e

f

g

h

i

j

k

1

m

n

o

$\mathrm{p}$

$\mathbf{q}$

r

$\mathbf{S}$

$\mathrm{t}$

$\mathbf{u}$

V
Operation and maintenance cost for the life cycle of the technology is estimated to be $\$ 50,000$ per year plus 120 labor hours each year for seven years.

Acquisition cost for equipment is approximately $\$ 120,000$.

NA

NA

NA

NA

NA

NA

Longest procurement lead times for custom or engineered components is estimated to be 6 months.

The dual-energy pulser and its respective analog-to-digital converter (ADC) interface, and the spectral analysis and control software are custom from INEL.

Two hours per month should be anticipated as unscheduled maintenance.

One hour per month should be scheduled for maintenance.

It is estimated that this technology will be available for field demonstration in one year.

It is estimated that this technology will be available for full operation in two years.

Senior support technician personnel with radiation measurement training are required to operate this equipment.

The labor hours to operate this equipment is two per clock hour of operation. Not known.

No permits are required beyond a license to possess and use a 5 to $10 \mu \mathrm{g}$ Cf-252 neutron source.

Allow two months to customize the commercially purchased equipment.

Electrical power in the form of 110 volts is needed to operate this equipment.

To train technicians to operate the equipment would take two weeks but does not include full capability to interpret the data.

Allow $\$ 45,000$ of equipment funds and 120 labor hours each year to cover contingencies. 


\subsubsection{System Tests}

3.1.1.1 Acceptance Tests. The following acceptance tests are required:

- Verify that all required system documentation is available. This includes, but may not be limited to, detector drawings, schematic diagrams, specifications, operational and maintenance manuals, external connector drawings and schematics, and output conversion factors (reference TS 3.11 of Appendix B).

- Verify the following system physical requirements. Verification shall be by inspection of documentation, visual inspection of the system, and/or appropriate tests, measurements or checks.

- Verify that the total weight of the operational system as delivered by the subcontractor does not exceed $200 \mathrm{lb}$. Verification shall be by weighing the system and recording the actual weight (reference TS 3.1).

- Verify that the external case is water resistant so that it can be easily decontaminated and still be easily opened for maintenance (reference TS 3.9).

- Verify that the detection system consists of two each plastic gamma scintillation detectors and two each He-3 neutron proportional counter detectors. The He-3 neutron detectors shall be in separate side-by-side neutron chambers separated by a $2.54-\mathrm{cm}$ thick polyethylene wall. Verify that the neutron chambers are covered by a $1.27-\mathrm{cm}$ thick sheet of polyethylene. The plastic gamma scintillators lay on the polyethylene sheet and shall each cover a neutron chamber (reference TS 3.3 and TS 3.4).

- Verify that the four detectors (two each gamma and two each neutron) are totally independent such that there are four separate and independent analog outputs (reference TS 3.7).

- Verify that a graded shield of tin and lead covers the back and sides of the plastic scintillation detectors (reference TS 3.5).

- Verify that military style connectors are used in the system. Verify that separate connectors are used for power and signals. Verify that mating cable connectors have been supplied along with spare connectors for each connector used in the system (reference TS 3.10).

- Verify that input system power is $+24 \mathrm{Vdc}$. Verification shall be by documentation inspection and visual inspection of system wiring (reference TS 3.6). 


\subsubsection{Characterization Tests. None.}

\subsubsection{Gamma Detector Tests}

\subsubsection{Acceptance Tests.}

3.1.2.1.1 Gamma Efficiency-The gamma efficiency of the plastic scintillators shall be measured using a Cs-137 source located $30 \mathrm{~cm}$ from the front face of the detector assembly. The efficiency shall be defined as the counting rate of each scintillation detector divided by the gamma-ray emission rate of the source. The emission rate of the gamma-rays is calculated from the output activity of the source at the last assay date, the gamma-ray emission probability, and the half-life of the isotope. The summed efficiency of the two plastic scintillators shall be equal to or greater than $2 \%$ (reference TS 3.4).

3.1.2.1.2 Count Rate-The count rate capability of the gamma-ray electronics shall be measured to verify a count rate capability of $1,000,000$ counts per second with less than $10 \%$ counting losses. Input counts to the electronics will be ideally from a pulser unit to a test input, if available. If no input point is available, an attempt should be made to attach the pulser to an acceptable point in the existing electronics circuit. If necessary, a check source (for example, Cs-137) can be used. Note, however, that the use of a check source will include the response of the scintillator. The technical specification of the RFP requires a minimum count rate capability for the electronics only. As a last resort, minor modifications to the electronics may be made to attach a pulser, but only after all other tests have been performed and accepted (reference TS 3.7).

3.1.2.1.3 Analog Output-The analog output signals from both gamma-ray detectors shall be measured to verify that (a) the analog output voltage is linearly proportional to count rate from $-5 \mathrm{Vdc}$ (zero count rate) to $+5 \mathrm{Vdc}(1,000,000$ counts per second) and (b) the output is capable of driving a 1 megohm load. These tests should be made using a pulser unit. Input rates in steps of 100,000 counts per second will be acceptable (reference TS 3.8).

\subsubsection{Characterization Tests.}

3.1.2.2.1 Neutron Efficiency-The neutron efficiency of the gamma-ray scintillation detectors shall be measured. Efficiency shall be defined in the same manner as in Section 3.1.2.1.1 above. An unmoderated $\mathrm{Cf}-252$ source shall be used for this test. If time and resources permit, the efficiency shall also be measured with one or more (up to five) plutonium accident dosimeter (NAD) 1-g sources.

3.1.2.2.2 Energy Range-The energy range of the gamma-ray detectors shall be measured and recorded. A series of different isotope check sources can be used for this test. Recommended check sources are Am-241 (59 keV), Cs-137 (662 keV), and either Co-60 $(1173+1332 \mathrm{keV})$ or Th-228 $(2.614 \mathrm{MeV})$. These tests may be performed in either of two ways. If a linear analog amplifier output is available whose maximum amplitude is known, the amplifier output amplitude can be measured as a function of energy. The maximum energy range would be equal to the product of the energy of the selected isotope and the ratio of the maximum output amplitude to the amplitude of the isotope pulses. Amplitudes can be measured using an 
oscilloscope. A similar method to determine the energy range is the use of the single channel analyzer built into the system. If the maximum full-scale discriminator setting is known, then the maximum energy can be determined by using a selected isotope, such as Cs-137, and adjusting the low-level discriminator to the point where counts just begin to appear for the isotope and measuring the discriminator voltage. The maximum energy is the product of the isotope energy and the ratio of the maximum discriminator voltage and the voltage at which counts just begin to appear.

3.1.2.2.3 Lower Limit of Detection-For the purposes of this test, the lower limit of detection is defined as the maximum distance from the face of the detector assembly for a given check source that results in a count rate at the analog count rate output that is at least twice the output of the ambient background at the location of the test. This definition requires the measurement of the background prior to the measurement of the lower limit of detection. Measurements should be such that the check source is placed normal to the center of the front face of the plastic scintillator and begin $30 \mathrm{~cm}$ from the front face of the assembly and increase in 10-cm increments. The check source should be Cs-137. Alternatively, all measurements will be made at a $30-\mathrm{cm}$ distance from the front face of the detector and the source strength lowered until the strength of a source that is $4.65 \sqrt{\mathrm{B}}$ can be deduced where $\mathrm{B}$ is the background.

3.1.2.2.4 Scan Speed-Scan speed is defined as the rate in feet per minute at which a given source can be moved parallel to the face of the detector assembly at a given distance and be detected with a count rate that is at least $50 \%$ of the count rate of that check source when located at the position normal to the center of the scintillator. The recommended distance is $30 \mathrm{~cm}$.

\subsubsection{Neutron Detector Tests}

\subsubsection{Acceptance Tests.}

3.1.3.1.1 Neutron Efficiency-The neutron efficiency of the He-3 detectors shall be measured using a Cf-252 source located $30 \mathrm{~cm}$ from the front face of the detector assembly. The efficiency shall be defined as the counting rate of each neutron detector divided by the neutron emission rate of the source. The emission rate of the neutrons is calculated from the output activity of the source at the last assay date, the neutron emission probability (neutrons per fission), and the half-life of the isotope. The summed efficiency of the two He-3 detectors shall be equal to or greater than $0.5 \%$ (reference TS 3.2 ).

3.1.3.1.2 Count Rate-The count rate of the neutron electronics shall be measured to verify a count-rate capability of 50,000 counts per second with less than $10 \%$ counting losses. Input counts to the electronics will ideally be from a pulser unit to a test input, if available. If no input point is available, an attempt should be made to attach the pulser to an acceptable point in the existing electronics circuit. If necessary, a check source (Cf-252) can be used. Note, however, that the use of a check source will include the response of the He-3 detectors. The technical specification of the RFP requires a minimum count rate for the electronics only. As a last resort, minor modifications to the electronics may be made to attach a pulser, but only after all other tests have been performed and accepted (reference TS 3.7). 
3.1.3.1.3 Analog Output-The analog output signals from both neutron detectors shall be measured to verify that (a) the analog output voltage is linearly proportional to count rate from $-5 \mathrm{Vdc}$ (zero count rate) to $+5 \mathrm{Vdc}(50,000$ counts per second) and (b) the output is capable of driving a 1 megohm load. These tests should be made using a pulser unit. Input rates in steps of 5,000 counts per second will be acceptable (reference TS 3.8).

\subsubsection{Characterization Tests.}

3.1.3.2.1 Energy Range-The energy range of the neutron detectors shall be measured. The possible methods available to make this measurement are identical to those used to measure the energy range of the gamma detectors. See Section 3.1.2.2.2 above.

3.1.3.2.2 Lower Limit of Detection-For the purposes of this test, the lower limit of detection is defined as the maximum distance from the face of the detector assembly for a given check source that results in a count rate at the analog count rate output that is at least twice the output of the ambient background at the location of the test. This definition requires the measurement of the background prior to the measurement of the lower limit of detection. Measurements should be such that the check source is placed normal to the center of the front face of the neutron detector and begin $30 \mathrm{~cm}$ from the front face of the assembly and increase in $10-\mathrm{cm}$ increments. The check source shall be Cf-252. Alternatively, all measurements will be made at a $30-\mathrm{cm}$ distance of the source from the front face of the detector and the source strength lowered until the strength of a source that is $4.65 \sqrt{\mathrm{B}}$ can be deduced, where $B$ is the background.

3.1.3.2.3 Scan Speed-The scan speed is defined as the rate in feet per minute at which a given source can be moved parallel to the face of the detector assembly at a given distance and be detected with a count rate that is at least $50 \%$ of the count rate of that check source when located at the position normal to the center of the scintillator. The recommended distance is $30 \mathrm{~cm}$. The recommended source is Cf-252.

\subsection{Test of the Gamma-Ray Spectrometer}

\subsubsection{Installation of Gamma-Ray Spectrometer}

The following steps are to install a gamma-ray spectrometer:

1. Using a source of Am-241 verify the $60-\mathrm{keV}$ gamma-ray peak lies above the lower-level discriminator with the gain set for $\sim 11 \mathrm{MeV}$ full scale (maximum gamma-ray channel).

2. Using a PGNAA setup (see arrangement used for assay of chemical agent with PINS $^{5}$ ), with a polyvinyl chloride (PVC) plastic sample, and a $\sim 5 \mu \mathrm{g} \mathrm{Cf-252}$ neutron source set the gain of the Ge spectrometer so that an acquired spectrum covers the energy range of interest (i.e., $\sim 200$ to $\sim 11,000 \mathrm{keV}$ ) and verify that no undesirable noise is entering the spectrum. 
3. Remove the Cf-252 source. Reintroduce the Am-241 source and verify that the $60-\mathrm{keV}$ gamma-ray peak lies above the lower-level discriminator.

4. Remove the Am-241 source. Reintroduce the Cf-252 using the PGNAA setup described above and reacquire a PGNAA spectrum of the PVC sample. Verify that the pulser peaks are in the upper portion of the spectrum reserved for them.

5. Verify that the VAXGAP family of programs are loaded and operating on the Microvax by the acquisition and analysis of a spectrum. Check that the display is operating, while a spectrum is being acquired, by entering the DAS command.

Suggestion: Use the DAS routine during spectral acquisition to check that the pulser peaks are in the correct channel regions reserved for them and that their widths are sharp with no apparent gain shifts.

6. Document the results of these measurements.

\subsubsection{Automatic Energy Calibration with Dual-Energy Pulser}

The following steps are used for automatic energy calibration with dual-energy pulser:

1. With a PGNAA setup as described in Step 2 of Section 3.2.1, acquire a spectrum that is suitable for energy calibration of the dual-energy pulser peaks $(\sim 50,000$ to 100,000 counts in the peak channel of the strongest gamma-ray peaks of interest). A plastic PVC cylinder provides a source of prompt capture gamma-rays of chlorine extending across the entire energy range from $516 \mathrm{keV}$ to above $8 \mathrm{MeV}$.

2. Store the acquired spectrum in its associated spectrum slot (with the $S 90$ command) and energy calibrate the pulser peaks with the automatic pulser energy calibration routine (using the $P E Q C L$ command).

3. Verify that the pulser pulses have been calibrated correctly by acquiring a second spectrum and scanning the stronger peaks of the entire spectrum-the energies of the gamma-ray peaks should lie within $1 \mathrm{keV}$ of the true energy.

4. Automatically analyze the spectrum with one of the automatic analysis programs (e.g., GNUL) and compare the known chlorine energies with the measured values; document the differences. Compare the energy resolution with that quoted by the manufacturer. It should lie within $5 \%$ of the manufacturer's measured value.

5. Verify that the radionuclide identification program is working properly by checking that the chlorine peaks are so identified (use CHEMLIBS isotope library). Label the spectrum using the HEAD command and save the spectrum in the save area. The spectrum ID should follow the following format: ADC ID (2 digits), month data acquired ( 2 digits), date data acquired ( 2 digits), year data acquired ( 2 digits), and the sequence of the count for that day (3 digits). Refer to the VAXGAP User's Manual for help with these or other commands. 
6. Disassemble the CE-252 source/moderator/shielding assembly, remove the PVC sample, and introduce a Co-60 source. Acquire a spectrum and analyze it with the automatic spectral analysis program or the interactive analysis program GINA. Measure the energy resolution of the 1,332-keV peak and compare to the manufacturer's measured and warranted value. The measured energy resolution should be within $5 \%$ of the warranted value. Measure the full-width-at-fiftieth maximum and compare to the manufacturer's warranted value. The measured value should lie within $5 \%$ of the warranted value.

7. Remove the Co- 60 source and replace it with a radioactive source of a radionuclide expected to be present in excavated waste (e.g., Cs-137, Eu-152). Acquire a spectrum and measure the deviations of the energies of the peaks from their true values. Analyze the spectrum using a decay data library (e.g., MASTER) tailored for longhalf-life radionuclides expected at a waste excavation site. The objective is for these peaks to lie within $1 \mathrm{keV}$ of their true values but this may not be the case for energies below $500 \mathrm{keV}$ or above $8 \mathrm{MeV}$.

8. Document these results.

\subsubsection{Suitability of One Gain to Cover Entire Energy Range of Ge Spectrometer}

One important determination to be made in order for the Ge spectrometer to meet its operational technical specifications is to determine if one gain setting is sufficient to cover the entire required energy range from $60 \mathrm{keV}$ (Am-241) to $11 \mathrm{MeV}$ (nitrogen prompt gamma-ray). If both gamma-ray decay data and prompt gamma-ray data can be acquired with one gain setting, the operation of the Ge spectrometer can be simplified. If not, other provisions will be required to permit the Ge spectrometer to be used to acquire both types of data.

1. With the above gain setting covering the energy region from $\sim 40 \mathrm{keV}$ to $11 \mathrm{MeV}$ acquire a spectrum of Am-241.

2. Examine the spectral data for the $60-\mathrm{keV}$ peak of Am-241. It should be defined by at least four channels. Analyze the spectrum using one of the analysis programs.

3. With the same gain setting and with the PGNAA setup, insert a sample containing hydrogen, chlorine, iron, or other high cross-section material with a number of prompt capture gamma-rays covering the energy range from $-500 \mathrm{keV}$ to $\sim 11 \mathrm{MeV}$. Acquire a spectrum and analyze it with the CHEMLIBS radionuclide library. Verify that the energies of the strong gamma-rays are within $1.5 \mathrm{keV}$ of the "true" values listed in the library. The energy values may not achieve this accuracy.

4. Record the results.

\subsection{PGNAA Measurements with the Gamma-Ray Spectrometer}

PGNAA measurements with this system, which employs a $\sim 5 \mu \mathrm{g}$ Cf-252 source, will be used to measure chlorine in waste or as a plume as a function of depth with a Cf-252-based PGNAA 
system using as a sample an 8-gal drum containing $\sim 40 \%$ chlorine (in the form of $\mathrm{NaCl}$ ) and sand. The soil thicknesses are simulated with the use of rectangular-shaped aluminum containers of $\sim 21$ in. height by $\sim 21$ in. width and 3 in., 6 in., or 12. in. in depth. These containers can be filled with soil and assayed singly or in a stack to simulate soil depths from 3 in. to 15 in. These measurements will also measure the depth of soil (up to $15 \mathrm{in}$.) that will attenuate the chlorine capture gamma-rays to the point that they cannot be observed (LLD $=4.65 \sqrt{B}$ ) in a 3,600-second count. The chlorine gamma-rays will be produced with a $\mathrm{Cf}-252$ source located either at the drum (transmission geometry) with the containers of soil between the drum and the Ge spectrometer or at the side of the Ge spectrometer (backscatter geometry) with the neutrons having to penetrate the containers of soil to interact with the chlorine in the drum. Results from these measurements shall be documented.

\subsubsection{PGNAA Measurements}

The following procedure is recommended for PGNAA measurements:

1. After setting up the PGNAA Ge spectrometer and source assembly, energy calibrate the PGNAA Ge spectrometer as described in Section 3.2.2.

2. Set up an 8-gal drum containing a mixture of sand and chlorine about 9 in. to 12 in. above the floor with room for the containers of soil to be placed between the detector and the 8-gal drum.

3. With the Cf-252/poly block/shadow shield in the backscatter geometry acquire counts with no soil covering the drum, and 3 in., 6 in., 12 in. and 15 in. of soil covering the drum. Save the spectra.

4. Repeat Step 3 for the transmission geometry.

5. Analyze the spectra for peak areas of the stronger gamma-ray peaks.

6. Plot the peak areas as a function of the soil depth. 


\section{SEQUENCE OF ACTIVITIES}

The basic sequence of activities for the FY-94 performance tests and PGNAA measurements will be as follows:

1. Requisition the neutron/gamma mapper with a specification that will meet the needs of the digface characterization project.

2. Rebuild aluminum soil containers constructed in FY- 93 so that they can be stacked and so that they can be handled safely (anchored to a base plate when in experimental use or in storage).

3. Upon delivery of the neutron/gamma mapper, check that all deliverables are present and that no visual damage has occurred in shipment.

4. Milestone: delivery of neutron/gamma mapper to be by July 1, 1994.

5. Install dual-energy pulser on Ge spectrometer and modify ADC to accommodate dualenergy pulser interface.

6. Develop a support mechanism for the Ge spectrometer with bismuth germinate (BGO) annulus so that this spectrometer can be either suspended from a crane or from the digface trolley.

7. Commence experimental PGNAA measurements.

8. Commence experimental measurements on neutron/gamma mapper.

9. Install gamma-ray spectral analysis software on Microvax computer.

10. Commence experimental measurements on Ge spectrometer without testing BGO annulus.

11. Complete FY-94 scope of work by August 31, 1994. 


\section{SAMPLING AND DATA}

No sampling is conducted. Data collection will be with standard radiation measurement equipment in the form of pulses or an analog signal that will be connected to a strip chart recorder. Standard acquisition techniques will be employed. Ge spectra will be analyzed with the VAXGAP family of spectral analysis programs.

BWID has pursued development of the digface concept based on the belief that it will contribute to protection of human health and environment during cleanup of certain types of hazardous sites. Table 2 attempts to summarize the applicability of the digface characterization system to this purpose in the context of Comprehensive Environmental Response, Compensation, and Liability Act (CERCLA) criteria listed in the BWID Test Plan Guidance. ${ }^{4}$ The data being collected during the FY-94 digface characterization field tests are needed to understand the system's basic capabilities for detecting dangerous or unexpected conditions during excavation of a hazardous site.

Table 2. Applicability of digface characterization to CERCLA criteria.

\begin{tabular}{ll}
\hline Criteria & \multicolumn{1}{c}{ Applicability } \\
\hline 1 & $\begin{array}{l}\text { The digface characterization system will provide possible warning of hazardous } \\
\text { conditions during site cleanup. The alternative is to detect these conditions after } \\
\text { they have been released and dispersed into the local environment, which may be a } \\
\text { containment structure of open air. }\end{array}$ \\
& NA \\
3 & Long-term effectiveness of site cleanup is not impacted by digface \\
characterization. & Digface characterization can potentially identify hazards before they are disturbed. \\
& The alternative approach cannot, leading to the probability that employment of \\
digface characterization can reduce the spread of contaminants and thus the \\
volume requiring treatment.
\end{tabular}




\section{DOCUMENT CONTROL}

\subsection{Data}

Copies of all data and validated data will be recorded in INEL registered logbooks or stored on personal or VAX computers. The PIs will be responsible for their respective data and store it in a project file. Copies of all data will be forwarded to BWID for backup storage. Reports of data and results of tests will be documented through letters or informal reports. The results of major findings will be reported at technical meetings or published in the open literature. All software programs and spectral data are copied bimonthly to a backup tape.

\subsection{Test Plan}

This test plan will be revised as required and controlled by the PIs responsible for these tests. Only the PIs can authorize deviations from this test plan. Deviations from this test plan will be documented in laboratory notebooks. Any changes that would represent a significant modification to the technical methodology and thereby impact other tasks within the digface characterization project will be discussed first with the primary PI, N. E. Josten. 


\section{ANALYTICAL METHODS}

No samples are analyzed. 


\section{DATA REDUCTION, VALIDATION, AND VERIFICATION}

\subsection{Data Quality Objectives}

Data quality objectives (DQOs) of the FY-95 work focus on determining the accuracy and precision that can be expected of the operational parameters for the gamma-ray/neutron and the gamma-ray spectrometer. These determinations will allow evaluation of the capability and performance achievable with these digface characterization instruments and methods. The DQOs for all specific parameter measurements should be at least $\pm 25 \%$. All of the data shall be internally consistent and representative of similar data taken for other projects as determined by the PI in charge of the measurements. Data will be validated by review of the test measurements by a second PI.

The data objectives for the gamma-ray/neutron radiation mapping and hot spot detector are listed below:

a. The scanner shall be able to assay a surface at a scan speed of $30-\mathrm{cm}$ per 10 seconds.

b. The plastic scintillation detectors shall have a summed efficiency for Cs-137 of $2 \%$ with an uncertainty of $15 \%$.

c. The neutron detectors shall have a summed efficiency for Cf-252 fission neutrons of $0.5 \%$ with an uncertainty of $25 \%$.

d. The gamma-ray/neutron detector shall be able to be decontaminated with decontamination solution under field conditions without solution entering the protective encasement.

e. The analog signal from the above detectors will be sensitive to variations of $\pm 10 \%$ in the signal and be visibly discernable from a chart recorder at both high and low count rates.

The data objectives for the gamma-ray spectrometer are listed below:

a. The gamma-ray spectrometer shall operate over a range of $50 \mathrm{keV}$ to $\sim 11 \mathrm{MeV}$ and still permit the measurement of gamma-rays as low as 60-keV (Am-241) and as high as $10.8 \mathrm{MeV}$ (nitrogen prompt gamma-ray).

b. The gamma-ray energy scale shall be automatically calibrated (under program control) with a sample of PVC plastic and a Cf-252 source providing the spectrum from which the pulser pulses are calibrated to be energy equivalent. The automatic calibration shall determine the energy scale from $50 \mathrm{keV}$ to $11 \mathrm{MeV}$ to within $2 \mathrm{keV}$ for all energies within this range.

c. The library used for the identification of radionuclides in waste at an excavation site shall be installed with the analysis program. 
The DQO for the PGNAA system is to determine the maximum depth of soil that can cover a waste container or waste plume and still detect ( $L L D=4.65 \sqrt{B}$, where $B$ is the background) chlorine by an assay on an 8-gal drum filled with sand containing $66 \%$ softener salt $(\mathrm{NaCl}), 40 \%$ chlorine, with $95 \%$ confidence.

\subsection{Data Reduction Scheme}

Data from the Ge spectrometer will be analyzed using the principles described in American National Standard N42.14 for the "Calibration and Use of Ge Spectrometers." The VAXGAP ${ }^{6}$ family of gamma-ray analysis programs will be used in conjunction with spectral plotting programs to analyze the Ge gamma-ray data. Energy calibration of the.Ge spectrometer will be performed using the method developed by E. W. Killian and described in the VAXGAP User's Manual. ${ }^{7}$ The gamma-ray/neutron data will be analyzed using techniques described in Reference 8.

The PI in charge of the specific test will be responsible for validating the acquired data.

\subsection{Data Reporting}

Data collected during these tests will be evaluated, peer reviewed, and documented in a letter to N. E. Josten, the primary PI of the digface characterization project. Copies of the letter will be distributed by the PI of the digface characterization project. 


\section{QUALITY ASSURANCE}

The quality level for these instruments and tests will be Level 3. All activities will follow the guidance in the EG\&G Idaho Quality Manual. The Quality Program Plan is QPP-044. The policies described in QP-15, "Control of Nonconforming Items," are invoked with the clarifications described in Sections 9.1-9.5. Quality control will be maintained by checking the condition of each instrument prior to taking measurements. In some cases this will be done with a check source. In other cases it will be done by inspection of the spectral data. All data will be inspected for consistency. Energy measurements will be made with gamma-rays whose energies are accurately known. When specific parameters are to be measured, the data quality objective shall be at least $\pm 25 \%$. Changes in any of the instrumentation will be the authority of the PI in charge of the test. The primary PI, N. E. Josten, will inspect the test activities and documentation at least once. 


\section{EQUIPMENT AND INSTRUMENTS}

The equipment required to run the test are:

1. Neutron/gamma mapper with power supply (24-Vdc, 2-amp power supply).

2. Ge spectrometer including detector, high voltage bias supply, amplifier, analog-to-digital converter, acquisition interface module, and VAX workstation or comparable computer (e.g., Radiation Measurements Laboratory computer, MAX).

3. Neutron excitation sources of Cf-252 and gamma-ray sources of Co-60, Eu-152, and Am-241.

4. Neutron and gamma-ray shielding.

5. Strip chart recorder with built in voltage calibration.

All of the above equipment must be able to function in a laboratory environment. 


\section{SUPPLIES, UTILITIES, AND FACILITIES}

Implementation of this test plan is dependent on the timely arrival of the neutron/gamma mapper, and availability of a machinist. The remainder of the work will be performed by the authors of this test plan or by other staff members within their organizations. The equipment requires $110 \mathrm{Vac}$ power. The facilities for performing this work are available in the TRA laboratories. 


\section{HEALTH AND SAFETY}

Safety is a priority concern with all measurements and experiments. These measurements will be performed under standard practices and procedures in accordance with the attached categorical exclusion (see Appendix D). These practices include Independent Safety Review Group approval and the operation under a Radiation Work Permit whenever a Cf-252 or other calibration or check sources are in use. All measurements will be in accordance with the TRA Health and Safety Plan. 


\section{RESIDUALS MANAGEMENT}

No hazardous wastes or residuals will be produced as a result of this activity. 


\section{REFERENCES}

1. J. L. Mayberry et al., Preliminary Systems Design Study Assessment Report, Vols. 1-8, EG\&G Idaho, Inc. EGG-WTD-9594, Vols. 1-8, 1991.

2. J. G. Richardson et al., INEL Operable Unit 7-13 Retrieval/Ex Situ Thermal Treatment Configuration Options, EG\&G-WTD-10204, 1992.

3. R. J. Gehrke, R. Aryaeinejad, K. D. Watts, D. R. Staples, and D. W. Akers, Application of PINS and GNAT to the Assay of 55-gal Containers of Radioactive Waste, EGG-NRE-11236, March 1994.

4. L. C. Rounds and J. K. McDonald, Buried Waste Integrated Technology Test Plan Guidance, EGG-WTD-9800, Rev. 1, January 1994.

5. A. J. Caffrey, J. D. Cole, R. J. Gehrke, and R. C. Greenwood, "Chemical Warfare Agent and High-Explosive Identification by Spectroscopy of Neutron-Induced Gamma-Rays," IEEE Transactions on Nuclear Science, 39, 5, 1992, p. 1422.

6. E. Wayne Killian and J. K. Hartwell, VAXGAP: A Code for the Routine Analysis of GammaRay Pulse-Height Spectra on a VAX Computer, EGG-2533, U.S. Department of Energy, May 1988.

7. E. Wayne Killian and D. A. Femec, Operator's Guide for VAXGAP, a Gamma-Ray Spectrum Analysis Package, EGG-2672, U.S. Department of Energy, August 1992.

8. U.S. Nuclear Regulatory Commission, Passive Nondestructive Assay of Nuclear Materials, D. Reilly, N. Ensslin, and H. Smith, Jr., (eds.), NUREG/CR-5550, LA-UR-90-732, March 1991. 


\section{Appendix A}

Conceptual Drawings Showing Use of Sensors at an Excavation Site 
$-\ldots$ 


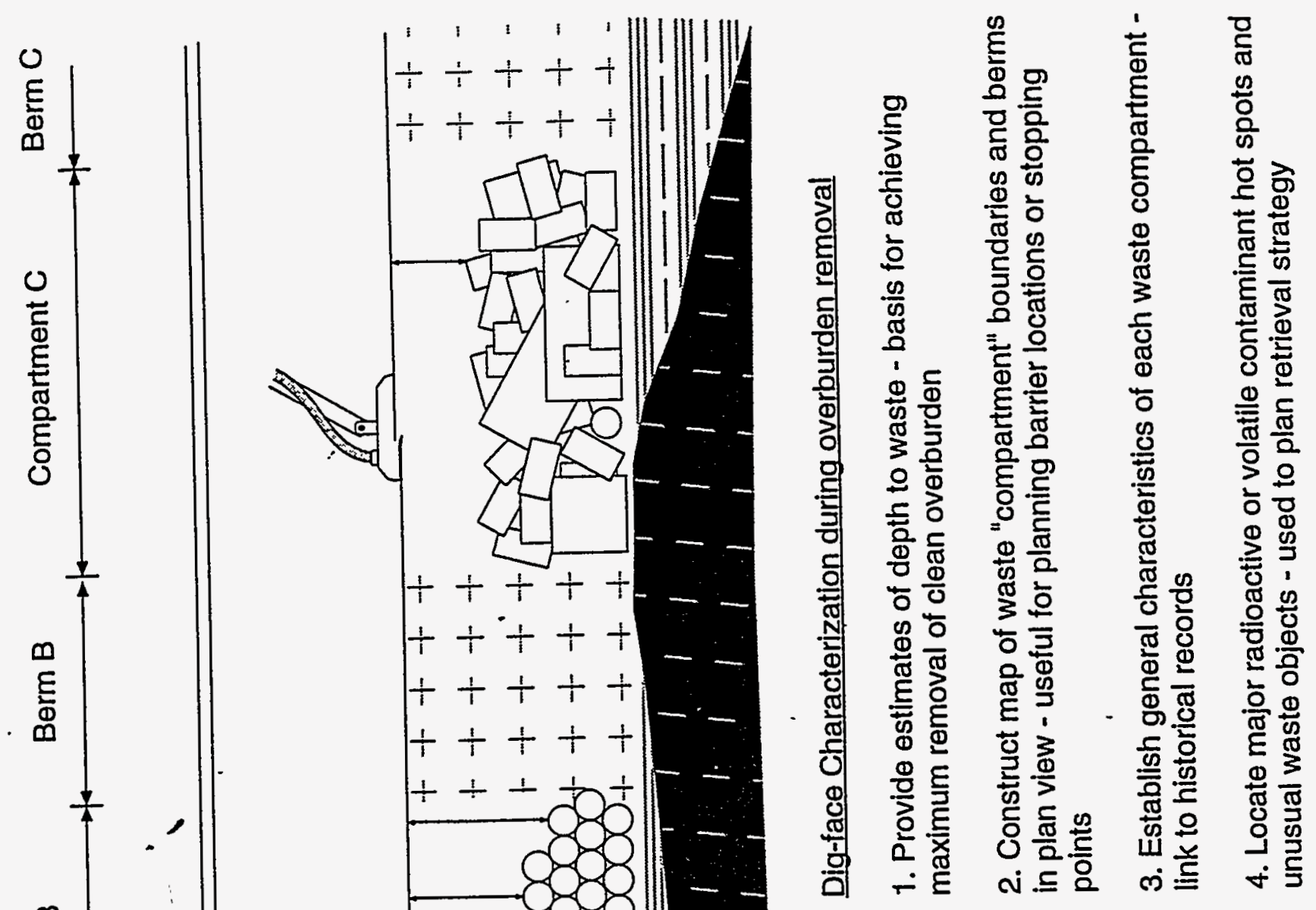




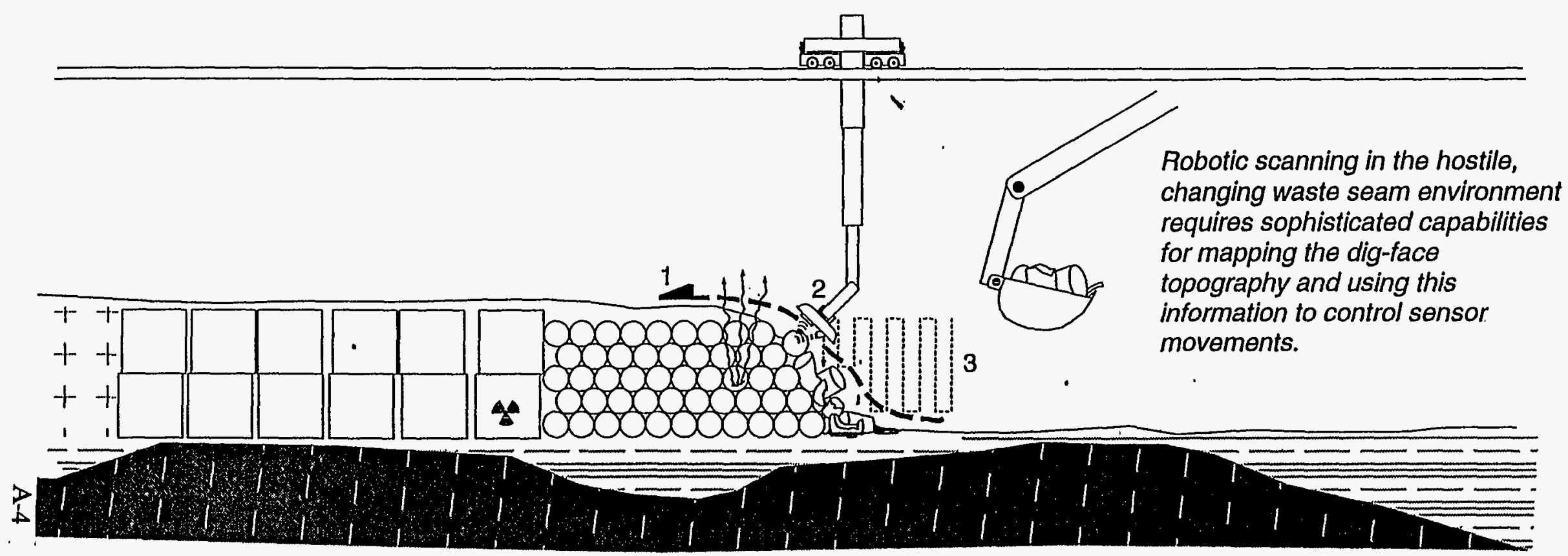

Waste Seam Excavation

1. Heavy construction style digging in hostile, uncontrolled environment of the waste seam

2. Assume all recovered material will require assay, but only a portion will require expensive processing or treatment

3. Waste seam environment changes constantly
Dig-face characterization during waste seam excavation

1. Routine scanning to monitor radioactive and volatile contaminant hot spots

2. In-depth in situ assay of exposed suspicious containers

3. Occasional systematic geophysical surveys to locate important objects such as reactor cores, vehicles etc. 


\section{Hot Spot Location}

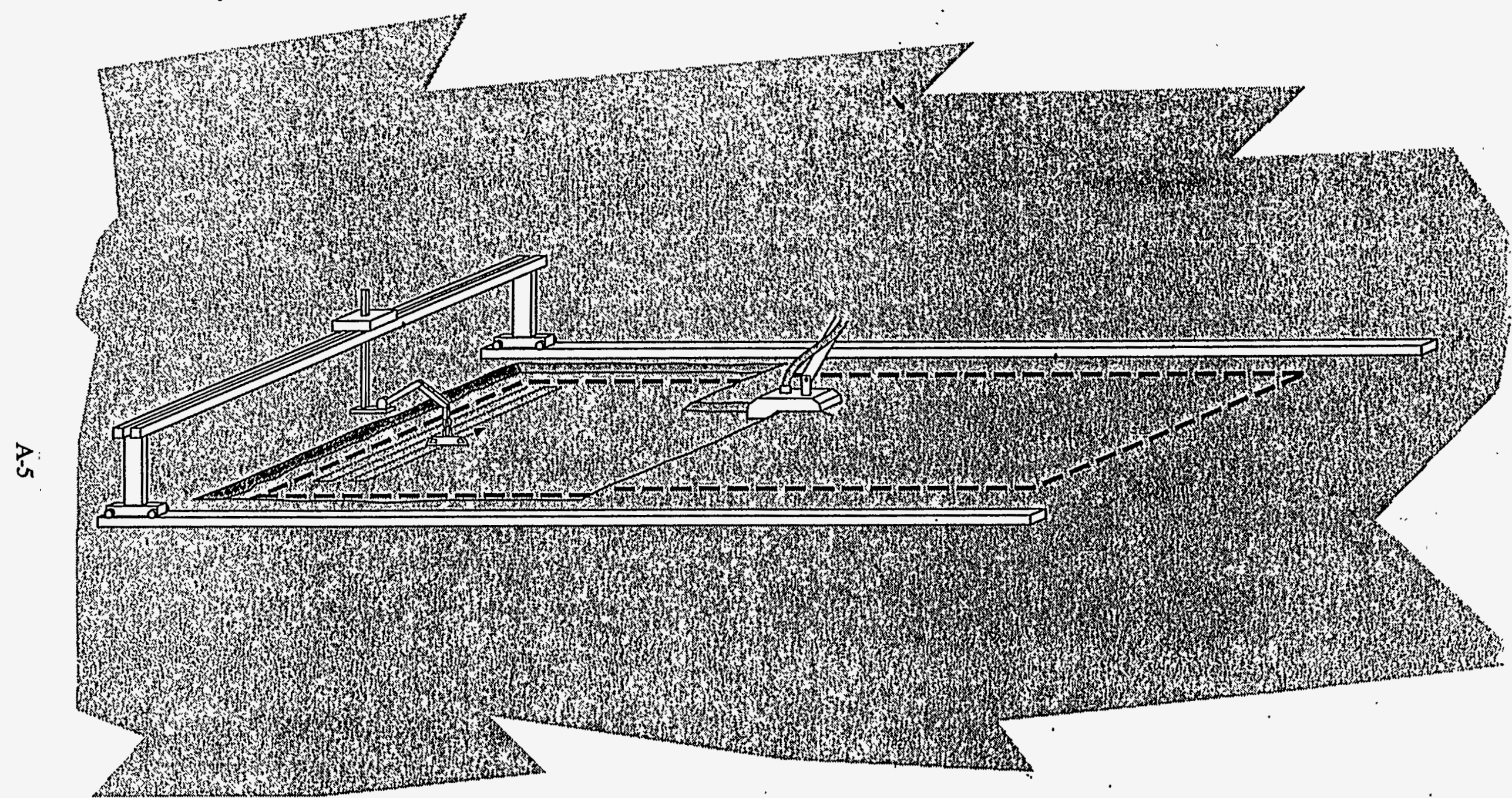

DFC system performs systematic surveys with geophysical and hazard sensors within a predefined search area. The objective is to locate two hot spots (one radioactive source, one volatile organic source) by elther detecting them directly or by detecting unique containers or waste configurations associated with them. If hot spots prove undetectable from the original ground surface, overburden is stripped in small increments followed by renewed characterization. 


\section{Complete Overburden Stripping}

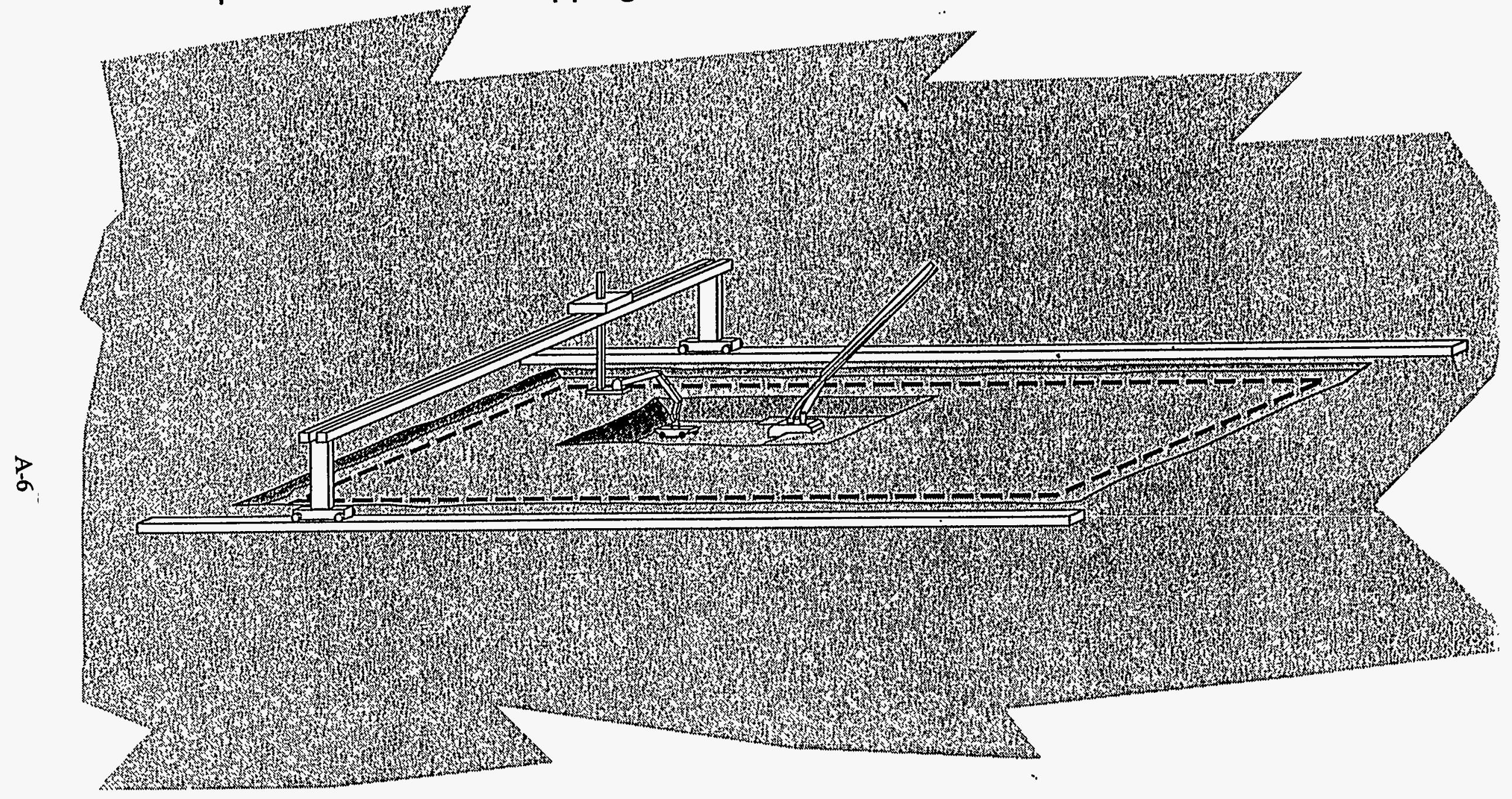

Remainder of overburden removed to form work space around each hot spot. DFC system performs systematic surveys to estimate proximity of waste to avoid contacting objects with excavator. PNL radar system may prove ideal for this purpose. At end of this phase, waste seam is exposed and hot spot has been precisely located in $X-Y$ plane. Also boundaries, berms, waste-free areas etc. are determined to assist in planning retrieval approach. 


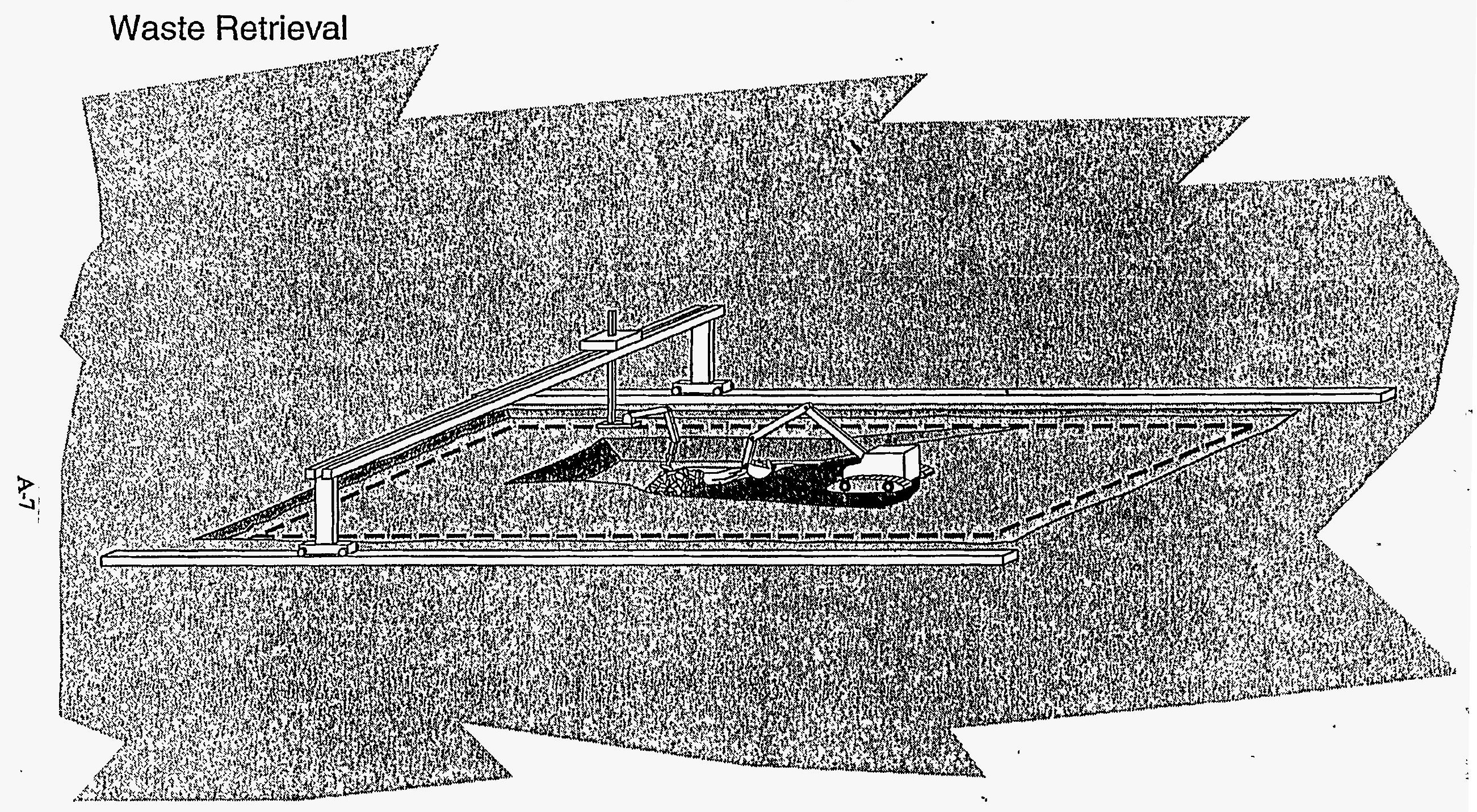

Access to hot spot gained by construction of trench into waste. Non hot spot waste removed and conveyed using full suite of BWID technologies. DFC system begins performing assay of exposed containers when retrieval nears hot spot location. At the end of this phase, a positive visual identification has been made of the hot spot source and plans are made for surgical removal. 


\section{Surgical Removal of Hot Spot}

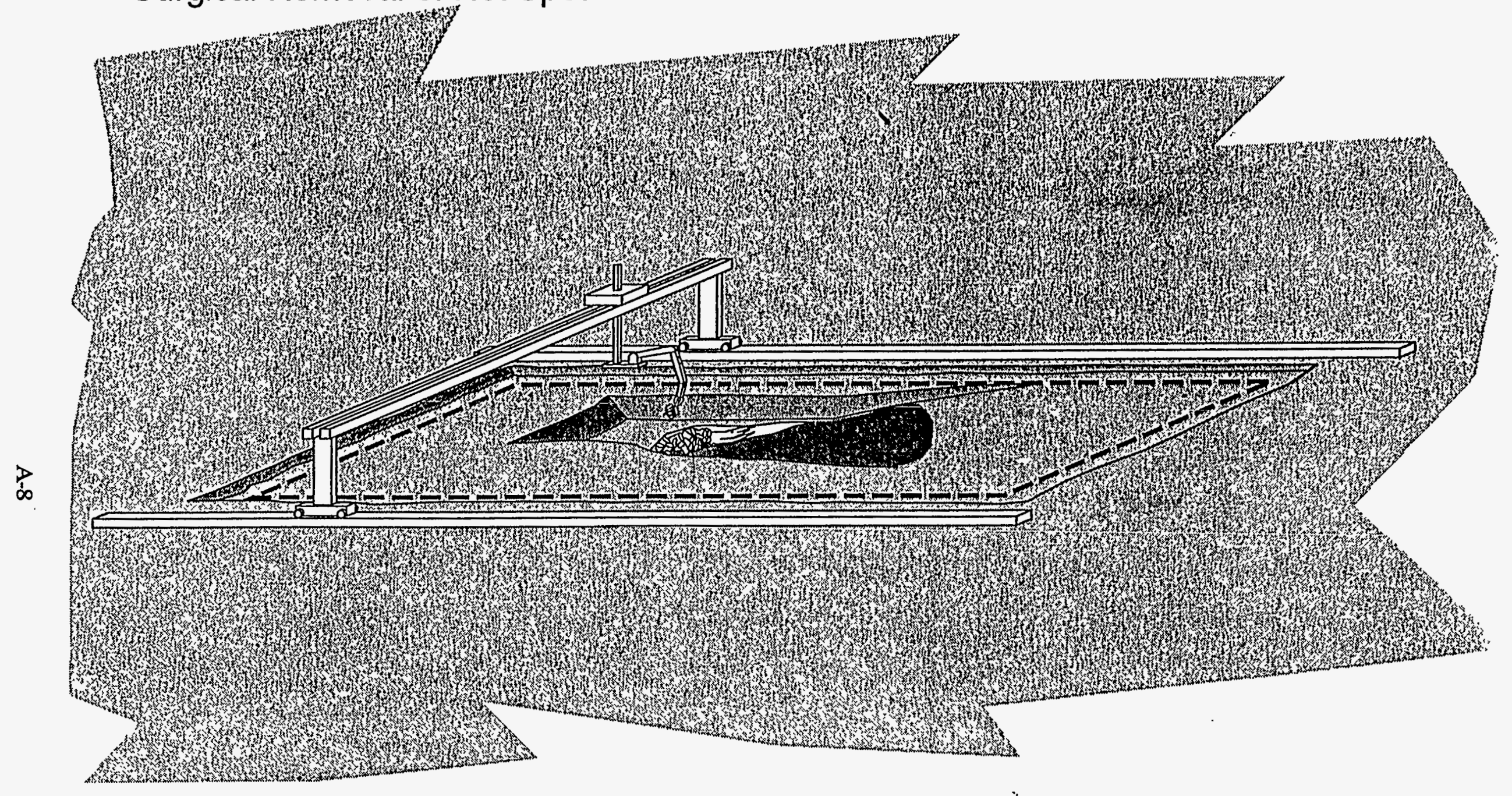

Source container removed by crane deployed equipment. DFC system then rescans dig-face to detect any contamination spread or presence of additional sources. 


\section{Appendix B}

Specifications in Request for Proposal for Gamma/Neutron Radiation Mapper 
$--\cdot-\ldots$ 


\subsection{Requirements}

3.1 The entire monitor assembly shall not exceed 200 pounds total weight.

3.2 Neutron detection shall be accomplished using two identical helium-3 proportional counters. These detectors shall be equal to or greater than 45 centimeters but less than 61 centimeters in length and shall be either 2.54 or 5.04 centimeters in diameter. Detectors of 2.54 centimeter diameter sball bo filled with ten atmospheres absolute of helium-3. Detectors of 5.04 centimeter diameter shall be filled with three atmospheres absolute of helium-3. The sumned. efficiency of the detectors in their experimental configuration shall be measured with neutrons emitted from a Cf-252 source located 30 centimeters from the front face of the detector assembly and shall be greater than or equal to 0.58 .

3.3 The two helium-3 detectors shall be installed side-byside inside a box-shaped neutron chamber constructed of polyethylene sides and back with thickness equal to or greater then 2.54 centimeters. A polyethplene wall the same thickness as the sides and back shall bo placed between the two detectors. This effectively creates two identical neutron chambers, each containing a single helium-3 detector. The front face of the neutron chambers shall be a single sheet of 1.27 centimeter thick polyethylene.

3.4 Gamma ray detection shall be accomplished using two identical plastic scintillation detectors. The thickness of each scintillation detector shall be equal to or greater than 2.54 centimeters but shall not exceed 3.81 centimeters. The area of the front face of each scintillation detector shall be approximately equal to the area of a single neutron chamber ( $s e \theta 3.3$ above) such that a single scintillation detector shall approximately cover a single neutron chamber. The summed efficiency from both gamma ray scintillation detectors shall be equal to or greater than $2.0 \%$ for gamma rays emitted from a Cs-137 source located 30 centimeters from the front face of the detector assembly.

3.5 A graded shield of 2 millimeter thick tin and 0.32 to 0.63 centimeter thick lead shall be placed around the sides and back of the plastic scintillation detectors. This shield is desirable to reduce the background gamma ray signals from sources not facing the front of the instrument. Deviations from this specification 
(due to overall weight restrictions) may be allowed but must be approved by the contractor. The plastic scintillator assembly with the tin and lead shield shall be placed in front of the 1.27 centimeter thick polyethilene front face of the neutron chambers assembly such that the tin/lead shield on the back of the scintillators is between the polyethylene and the plastic scintillators.

3.6 The gamma ray - neutron monitor shall accept +24 volt direct current for primary power. The design shall provide internal power and signal conditioning and incorporate accepted design practices to optimize signal to noise ratio. The design shall minimize interference from external noise sources including gasoline engine spark, if and microwave radio transmission, etc.

3.7 Bach of the four radiation detectors (two each neutron and two each gama ray) shall have independent and complete electronic signal processing systems such as preamplifiers, amplifiers, counters, etc. The helium-3 neutron detector electronics shall be capable of count rates to 50,000 counts per second with less than 108 counting losses. The plastic scintillator gamna ray detector electronics shall be capable of count rates to $1,000,000$ counts per second with less than $10 \%$ counting losses.

3.8 The electronics for each of the four detectors shall be designed as pulse counting systems. The output signals for each detector shall be proportional to counts per unit time. The unit shall provide an analog output signal for each detector. Digital output may also be provided at the discretion of the subcontractor, but is not mandatory. Analog signals shall be linearly proportional to count rate and shall be from $-5 \mathrm{VdC}$ to $+5 \mathrm{Vdc}$ at the maximum count rate. Analog outputs shall be capable of ariving a 1 megohm load.

3.9 The entire detector assembly, including electronics, shall be hermeticaliy sealed inside an external case material (material to be approved by contractor scientists) that is easily decontaminated by scrubbing or submersion within a decontamination solution. The external case shall be capable of being easily opened for detector and/or instrumentation maintenance.

3.10 Connectors for power and signals shall be military style connectors. Separate power and signal connectors shall be provided. However, signals for all four detectors may use a single connector. The 
subcontractor shall provide three identical spare connectors for each connector used in the system plus mating connectors for all installed and spare connectors.

3.11 Documentation consisting of detector drawings, schematic diagrams, assembly drawings, specifications, and operational and maintenance manuals shall be provided by the subcontractor. External connection schematics and analog output conversion factors shall be explicitiy provided in the documentation.

4.0 Deliverables

There are two specific deliverables for this procurement. The first is a working gamna ray: neutron monitor built to the specifications and requirements described in this Technical specification Document. The second deliverable is documentation describing calibration procedures, input and output schematics, theory of operation (i.e. time lags and constants), and analog to digital conversion factors in concert with section 3.11 of this specification.

4.1 The system shall be delivered to the contractor on or before July 1, 1994 . 


\section{Appendix C}

Chapters 2 and 5 of GNM-620 Operating and Service Manual (Gamma/Neutron Radiation Mapper) 


\section{INSPECTION AND SET-UP}

\subsection{INSPECTION}

The following procedures should allow on-site personnel to correctly set up the GNM-620 for normal operation. Follow the procedures in the order given.

\subsubsection{Incoming Inspection}

Immediately inspect the instrument for mechanical damage, scratches, dents or other defects. It should be examined for evidence of concealed, as well as external damage.

\subsubsection{Damage Claims}

If the instrument is damaged in transit or fails to meet specifications upon receipt, notify the carrier and TSA Systems, Itd. immediately. Shipping cartons, packing materials, waybills and other such documentation should be preserved for the carrier's inspection.

TSA will assist in providing replacement or repair of the instrument if necessary.

\subsubsection{Storage}

The GNM-620 should be stored in a dry, temperature constant location, and care should be taken to avoid subjecting it to severe mechanical or environmental shock.

\subsubsection{Shipping}

Before returning the instrument for any reason, notify TSA Systems of the difficulty encountered, giving the model and serial numbers of the equipment. TSA will furnish specific shipping instructions.

\subsection{SET-UP}

NOTE: THE GNM-620 IS NOT EQUIPPED WITH A POWER SWITCH. IT IS ON WHENEVER IT IS CONNECTED TO POWYER.

Connect the hand-held terminal to J3 on the GNM-620. 
The GNM-620 requires 18 to $36 \mathrm{Vdc}$ power at approximately 5 amps. Connect the power cable to the host vehicle power system. Observe polarity, pin A is positive and pin B is negative.

The terminal will turn on, run a power-on self-test and begin displaying the counts from the four detectors.

Press "F1" on the terminal to view or set the full-scale value for the gamma channels. The default is 50,000 counts for +5 volts out. Input a new value from the keypad and press "ENTER". Press "ENTER" to accept the displayed value.

Press "F2" on the terminal to view or set the full-scale value for the neutron channels. The default is 500 counts for +5 volts out. Input a new value from the keypad and press

"ENTER". Press "ENTER" to accept the displayed value.

This utility allows the operator to calibrate the GNM-620 to the analog recording device. The analog output will swing from maximum negative to 0 to maximum positive output. Press F5 on the terminal to access the DAC control utility. All four DACs are all loaded with Os, the analog outputs will be -5 volts. Pressing "F5" again will load the DACs with 127 , the analog outputs will be 0 volts. A third press on "F5" loads 255 , the analog outputs will be +5 volts.

\subsection{DISCRIMINATOR ADJUSTMENT}

The discriminator adjustments are located on the barrier plate on the right side of the enclosure. They are labeled to indicate upper and lower for both the gamma and the neutron channels.

2.3.1. GAMMA DISCRIMINATORS: The GNM- 620 has two controls which may be used to "tailor" it to specific site applications. The controls are the Upper Level Discriminator (ULD), and the Lower Level Discriminator (LLD) for the gamma channels. The factory settings will not cover all operating conditions. The discriminator window may be optimized for site specific requirements. See Drawing 3 for the location of the discriminator controls.

The upper level discriminator (ULD) and lower level discriminator (LLD) set the range of energy levels in which the system takes counts. The maximum range is between $0 \mathrm{keV}$ and $2 \mathrm{MeV}$. Multiplying the dial setting by 200 will yield the nominal $\mathrm{KeV}$ level; i.e. a setting of .3 on the LLD will indicate a low level discriminator setting of $60 \mathrm{KeV}$ above the noise level of the amplifier.

NOTE: THIS RELATIONSHIP IS AN APPROXIMATION. DUE TO MINOR VARIATIONS IN THE DETECTORS AND ELECTRONICS, THE EXACT VALUES WILL VARY SLIGHTLY. AS EXACT VALUES ARE SITE SPECIFIC AND MUST BE VERIFIED EMPIRICALIY, ALL VALUES GIVEN IN THIS MANUAL ARE RECOMMENDATIONS ONLY. 
Factory settings are as follows:

$$
\begin{aligned}
& \text { LLD: } 0.2 \text { turns }=20 \mathrm{keV} \\
& \text { ULD: } 10 \text { turns }=2 \mathrm{MeV}
\end{aligned}
$$

\subsubsection{NEUTRON DISCRIMINATORS}

The neutron discriminators are electronically similar to the gamma discriminators, but serve a different purpose. The neutron discriminators allow the system to only count neutrons that fall within the proportional operating region of the detectors. The GNM-620 is shipped with the neutron discriminators set as follows:

$$
\begin{aligned}
& \mathrm{LLD}=1.0 \text { volt } \\
& \mathrm{ULD}=10.0 \text { volts }
\end{aligned}
$$

In most circumstances, these settings should not require further adjustment.

\section{OPERATING INSTRUCTIONS}

WARNING: THE GNM-620 IS MOUNTED IN A WATER TIGHT CASE WITH LIMITED PENETRATIONS. ALL PENETRATIONS ARE SEALED WITH SILICON SEALER. IF THE BOLTS OR CABLES THAT PENETRATE THE ENCLOSURE ARE DISTURBED, THEY MUST BE RESEALED TO PRESERVE THE INTEGRITY OF THE ENCLOSURE.

The system was designed to withstand submersion in water for brief periods to allow decontamination. Do not leave the system submersed in liquid for extended periods of time.

\subsection{POWER-UP AND SELF-TEST}

When the unit is powered up, it performs a memory test on the RAM, and automatically begins counting.

\subsection{NORMAL OPERATION}

'After the set-up has been performed, normal operation involves mounting the GNM-620 onto the host vehicle, connecting the input power and the analog recording device. The GNM-620 is now ready for operation. 


\section{MAINTENANCE}

\subsection{CALIBRATION}

WARNING: THUS PROCEDURE INVOLVES HIGH VOLTAGE AND SHOULD ONLY BE DONE BY QUALIFIED PERSONNEL!!!

Equipment needed:

- Gamma test source $\left(5-10 \mu \mathrm{Ci}{ }^{137} \mathrm{Cs}\right.$

- Neutron test source (TSA uses $100 \mathrm{mCi} \mathrm{AmBe}$ )

- DVM

- Oscilloscope

- High voltage probe $5 \mathrm{kVdc}, \geq 1,000 \mathrm{~m} \Omega$ input $Z$

\subsubsection{Gamma Channels}

The gamma channels use HHV-448 and SCA-452 number 2 in the system. For the other HHV-448 and SCA-452 refer to the neutron channel calibration, section 5.2 in this manual.

\subsubsection{BHV-448}

The HHV boards are located under the barrier plate. Remove the two outer screws and swing the barrier plate in to gain access to the board.

While following this procedure refer to the schematic diagram and component designator (drawings 4 \& 5).

Connect the high voltage probe ( + ) to the H.V. connection on the HHV-448 board and the ground to chassis ground or the COM. connection on the HHV-448 board. Tum on the DVM. 
Adjust $\mathrm{R} 1$ on the board to achieve a reading of $1050 \pm 50$ volts DC. If the voltage will not reach this level or is not stable within \pm 5 volts, the board must be replaced.

Perform this procedure on each HHV-448 board in the system.

\subsubsection{2. $\mathrm{SCA}-452$}

\section{CAUTION： BEFORE PROCEEDING MAKE SURE THAT THE HIGH \\ - VOLTAGE TO THE DETECTORS IS SET TO 1050 VDC PER THE HHV-448 CALIBRATION PROCEDUTRE.}

While following this procedure refer to the schematic diagram and component designator (drawings 7 and 8 respectively).

Disconnect the inputs from the SCA board by removing the wires from $\mathrm{J} 1$; $\mathrm{J} 2$ and J3*. Connect the DVM from ground jumper X4 (-) to R94 ( + ) on the end closest to J6, then by adjusting $\mathrm{R} 95$ obtain a reading of 10.00 volts on the DVM. This is the reference voltage to the discriminators.

Leave the common lead of the DVM on the ground jumper X4, and move the other lead to TP2 on the SCA board. Adjust R14 to obtain a reading of -5.0 millivolts on the DVM. Move the lead from TP2 to TP4 and adjust R43 to obtain a reading of -5.0 millivolts. Move the lead to TP6* and adjust R77 for a reading of -5.0 millivolts. This adjusts the offset of the gain stages.

Connect the oscilloscope to the SCA-452 board and set as follows: vertical input to TP2 and probe ground to $X 4$. Set vertical deflection to 1 volt/division, horizontal sweep speed to 0.5 microseconds/division and positive edge triggering. Place the source in the center of the chamber to be calibrated. The signal seen should resemble drawing 14 "Typical Pulse Profile."

If not, adjust $\mathrm{R} 7$ on the SCA board to obtain a 3.3 volt \pm .3 volts pulse height. Move the probe to TP4 and ensure that the source is in the center of the chamber being calibrated. Adjust R37 for the same pulse height. Move the probe to TP6* and ensure that the source is in the center of the chamber that is being calibrated. Adjust R68 for the same pulse height. The other adjustments are factory set and should not be attempted in the field.

Repeat this procedure for all SCA-452 boards in the system.

*TP6 will only be installed on three channel SCA boards.

\subsubsection{Neutron Channels}

The GNM- 620 has been designed to require very little maintenance. However, the calibration should be checked periodically and whenever any repairs have been made. 
NOTE: ALWAYS CALIBRATE THE HIGH-VOLTAGE BEFORE ADJUSTING THE AMPLIFIERS ON THE SINGLE CHANNEL ANALYZER. THE HIGH VOLTAGE SETTING WILL CHANGE TEIE PULSE AMPLITUDE THAT IS SENT TO THE SCA-452.

\section{CAUTION: THE FOLLOWING PROCEDURES INVOLVE HIGH VOLTAGE AND SHOULD ONLY BE PERFORMED BY QUALIFIED PERSONNEL!}

\subsubsection{HHV-448}

The HHV boards are located under the barrier plate. Remove the two outer screws and swing the barrier plate in to gain access to the board.

While following this procedure refer to the schematic diagram and component designator (drawings $7 \& 8$ ).

Measure the high voltage at the output of the HHV- 448 board using a high voltage probe and a DVM. The high voltage should be $+1,350 \pm 50$ Vdc. If it is not, adjust $R 1$ to obtain the proper output.

If the output cannot be properly adjusted, or if it is not stable within $\pm 5 \mathrm{Vdc}$ the board must be repaired or replaced.

\subsubsection{SCA-452}

Remove the inputs from the SCA board by unplugging the wires from J1 and J2.

\section{Discriminator Reference Voltage}

Connect a DVM between ground jumper X4 and R94 on the end closest to J6. Adjust R95 for a reading of $10.000 \pm 0.005 \mathrm{Vdc}$.

\section{Amplifier Offset Adjustment}

Connect the DVM between ground jumper X4 and TP2 on the SCA-452 board. Adjust R14 for a reading of $-0.005 \pm 0.001$ Vdc.

Connect the DVM between ground jumper X4 and TP4 on the SCA-452 board. Adjust $\mathrm{R} 43$ for a reading of $-0.005 \pm 0.001 \mathrm{Vdc}$.

\section{Amplifier Gain Adiustment}

Reconnect the SCA-452 input cables to $\mathrm{J} 1$ and $\mathrm{J} 2$.

Connect an oscilloscope probe from ground jumper X4 on the SCA board and TP2. 
Place a test source on the right hand gamma detector.

The peak pulse amplitude should be +6 volts \pm 0.2 volts. If necessary, adjust $R 7$ to obtain the proper pulse amplitude.

Move the oscilloscope probe from TP2 to TP4 on the SCA-452 board.

Place a test source on the left hand detector.

The peak pulse amplitude should be +6 volts \pm 0.2 volts. If necessary, adjust $R 37$ to obtain the proper pulse amplitude.

This completes the calibration of the neutron channels. 


\section{Appendix D}

\section{Documentation for NEPA Categorical Exclusion (CX) for Radiation Measurements Laboratory at Test Reactor Area}


-

\section{.}


DATE: August 19, 1992

WECT: Categorical Exclusion (CX) for Radiation Measurements Leboratory (AM/SES-ESO-92-329)

70: Carol M. Borgstrom, Director. . Office of NEPA Oversight

DOE-HQ, EH-25

DOE-ID has reviewed and approved the subject CX (attached). This approval is based on Seciion " $D$ " NEPA detarmination authority delegated by the Assistant Secretary for Nuclear Energy. This CX supporis indoor bench-scale research projects in the Radiation Measurements Laboratory at INE['s Test Reactor Area.

DOE-ID is forwarding the approved CX for EH-25 review. PTease direct any comments or questions to Roger Twitchell at (208) 526-0776.

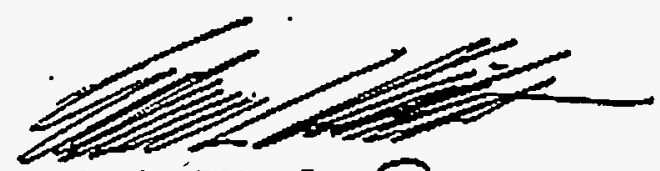

A. A. Pitrolo

Manager

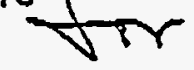

Attachment

C6 W/att: R. Sharma, DOE-HQ, NE-47 


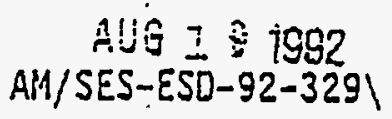

EXTERNAL DCE DISTRIBUTION:

$N / A$

IO DISTRIBUTION:

ESO File $(y)$

ESD Reading File (g)

Peggy Hinman

Teresa Perkins

Roger Twitchell

- Bob Jones, is 1133

\section{RECORO NOTES:}

\section{CONCURRENCE:}

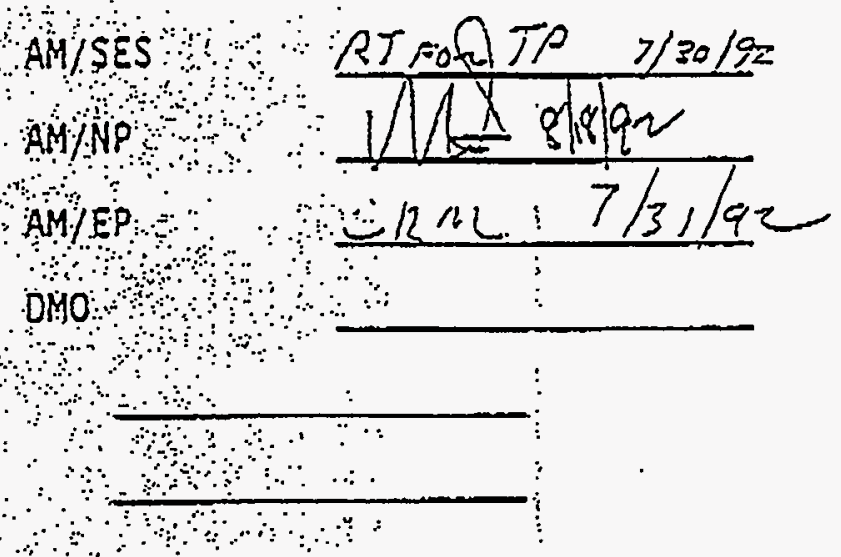

1. The attached $C X$ was prepared to cover routine laboratory operations and bench scale research at the Radiation Measurements Laboratory. : The specific event that made the preparation of this CX. advisable was a Work-ror-Others (WFO) project for the National Institute of Standards and Technology (NIST). With the approvalofthis CX, future bench.scale research projects at the radiationimensurements.lab can be undertaken with a letter to the file documenting. that the project fits within limits of this particular CX.

2. This CX was prepared by EGaG in coondination with Roger Twitcheil (SES) and the NEPA Compliance Officer Teresa Perxins (SES).

3. The attached correspondence has no refution to the Navat Nuclear Propulsion Program. Naval Reactors concuripence is not required.

RLTwitchel1 (SE\&S): rrhickey, x6-6521:7/29/92, A:SAMPLTR.CX (FiTe 6./.6.4 
RESOLRCE CAMCERY

TERRESTRIAL

Threasened/Sncingered Wi id?iti

Thisarened/Encangared Planss

प्रjidl/Fe/Vegezatien

Solis/Erosion

Culturaihiszoriza!

WI liamers/Seanie Aress

Prima/Unique Famland

WATER REEOLRCES

Wild/Seenie Rivers

Lakes/F iocciplains/Wet lands

Ocmestic/Greuniwater

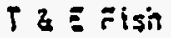

AIR RESOLRCS:QUALIT

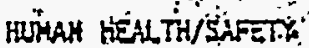

Socicesunenie Conesms

COMKETT:
A

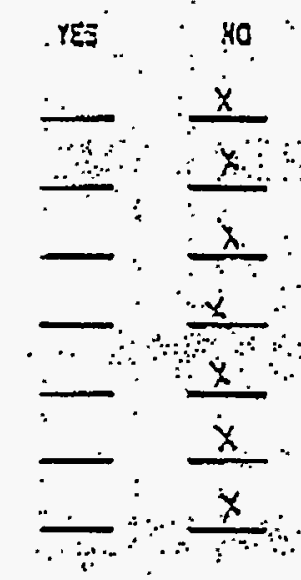

CHHEXT

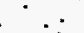




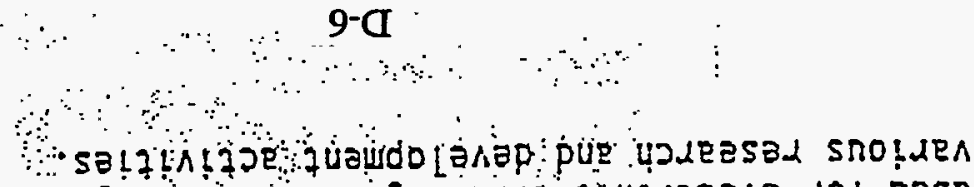

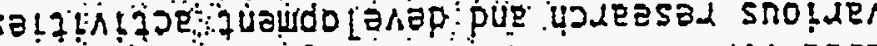

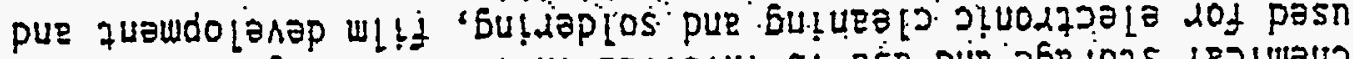

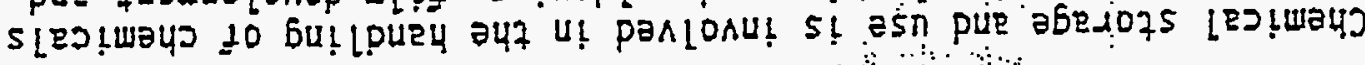

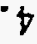

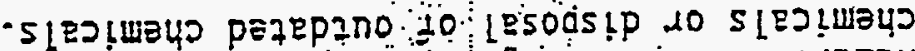

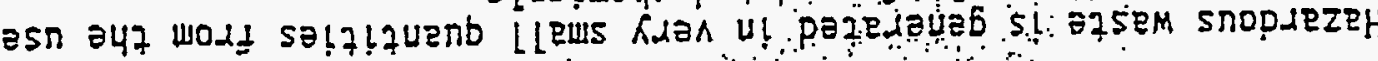

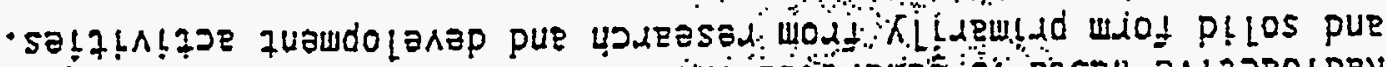

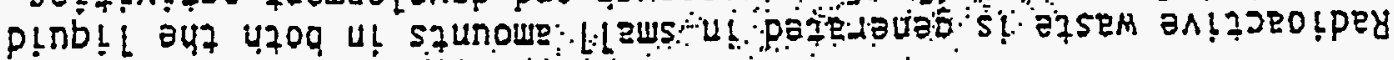

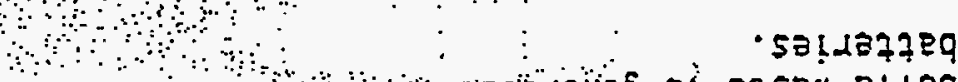

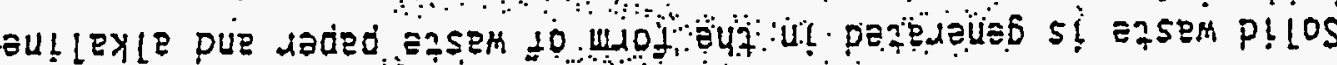

- pep!nodo

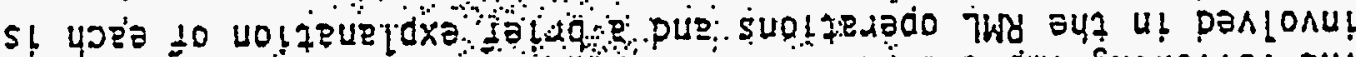

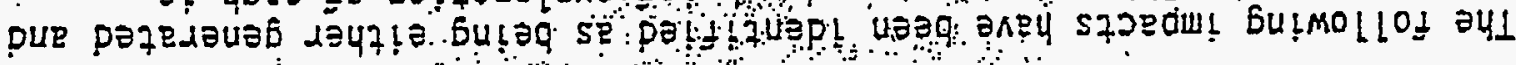

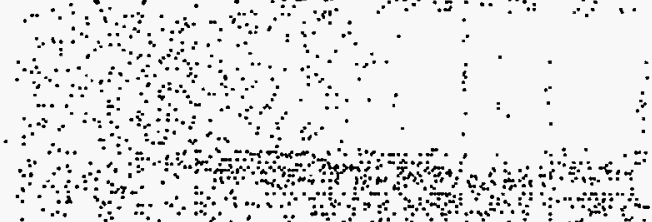

:572EdUI JO SEDAnOS

- $54 \div 5 E 3 \alpha 53 p$

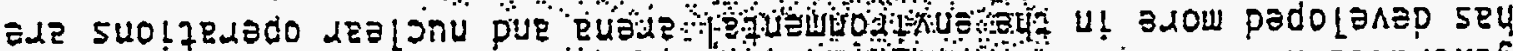

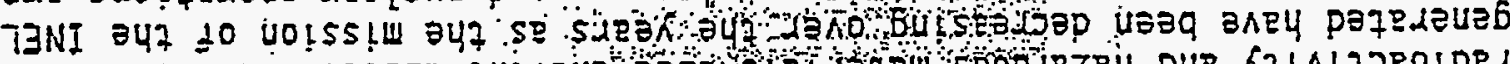

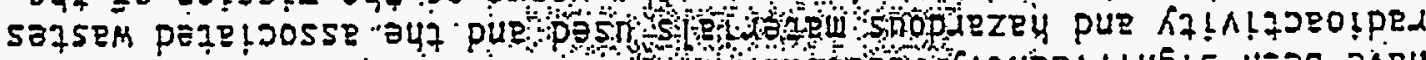

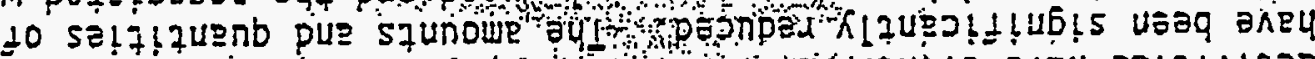

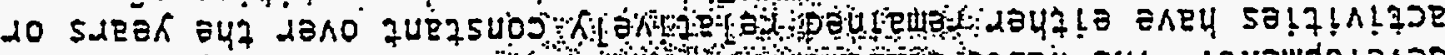

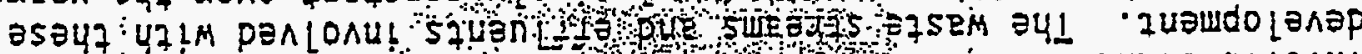

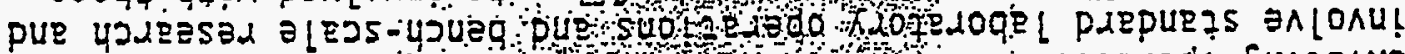
5อ!子!

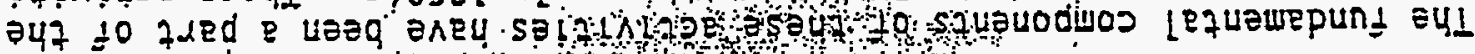

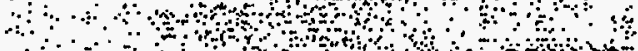

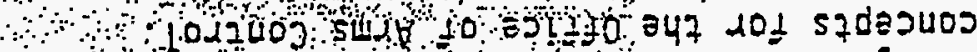

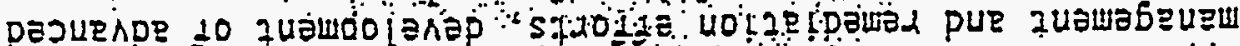

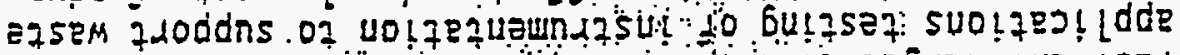

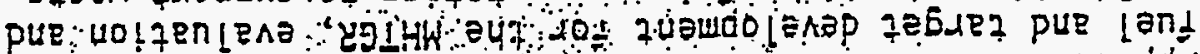

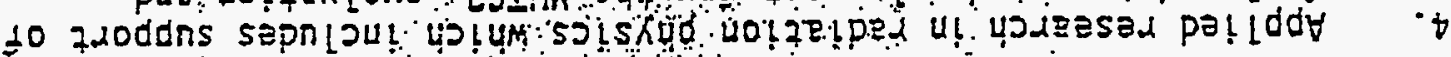

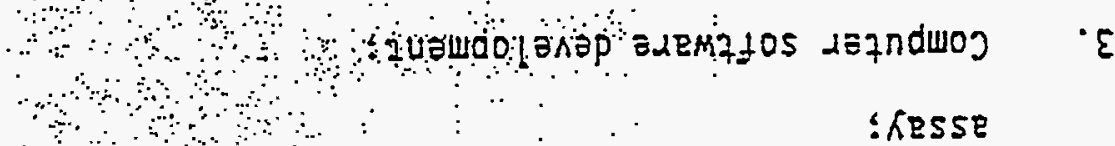

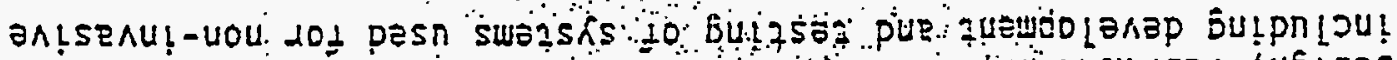

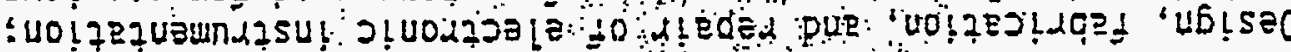

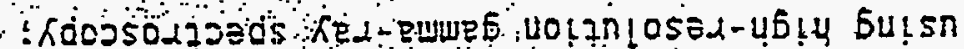

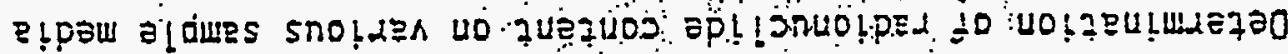

$\therefore: 5 \theta ! 3 ! \Lambda ! 37264 ! 00$

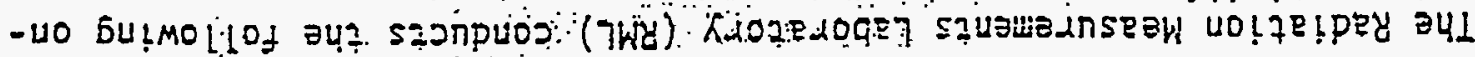

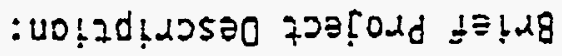

ᄉEO

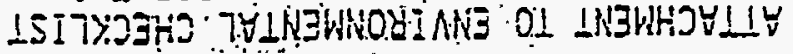


ATTACHMENT: RML Environientat Checkl ist.

Page 2

Sources of Impacts (continued):

5. Radiation exposira coutd os involyed dus to the handing of sealed sources or due to the: recuivements that a job be performed in a radiation area. ALARA joals arestablished:and maintained and reviews are conducted of high exposure activities to minimize exposures received.

The above impacts are involived wifheki operations and no new waste streams are identifiled, no effluent's ere increasing, and no: environmenta7: impacts have begh tidentified besed on the RML!s operations. Hasta streanis and mistonsisill ramain unchanged if not actually decreased by baste mirnimization and recycing.

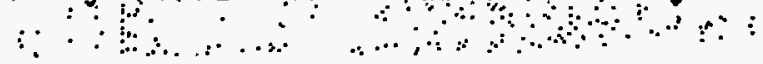




\section{U.5. DEPARTHEMT OF EHEREY :- IDAHO FIEID OFFICE}

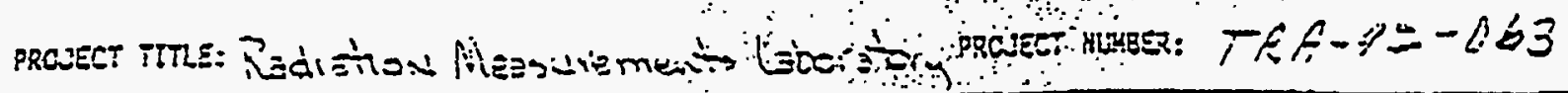

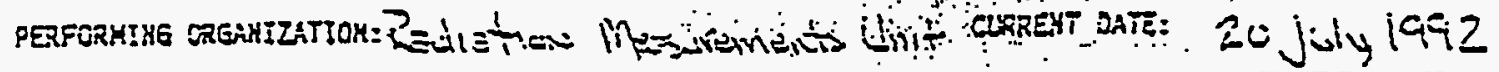

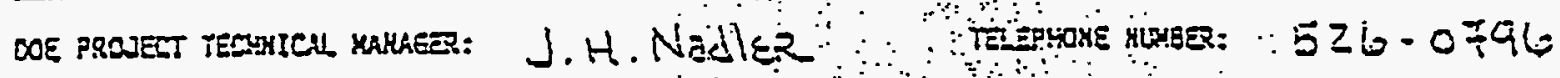

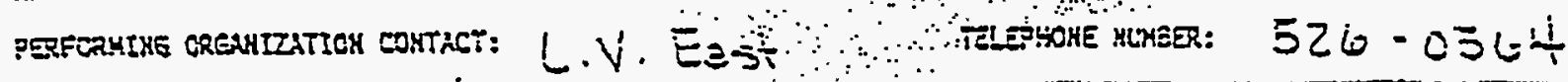

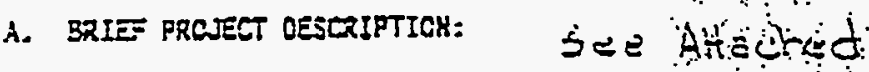

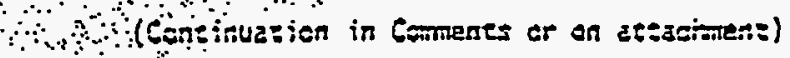

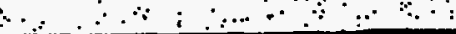

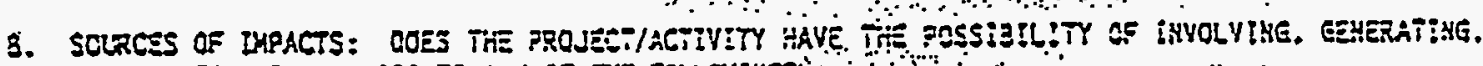

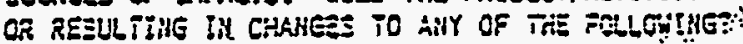

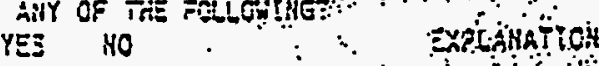

1. AIR POLLUTANTS

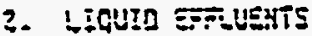

3. SALIO WASTE

$\therefore$ RAOTOACTIVE VASTE

三. HAZARTCUS WASTE

3. YYXSD HAST:

7. COZHICAL STORAESILSE

3. FETROLIIS FRCOUC:S STOPAE

@. AิธอีESTOS HASTE

i0. WATE USE/OIVESTCN

11. Firis: 5YSTE4

13. C! BARiHe/EREMATIOK

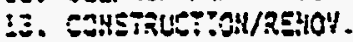

14. EXEESS YO:SE IEVE:

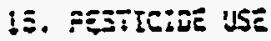

i5. 3AOHATICH EXPOSURE

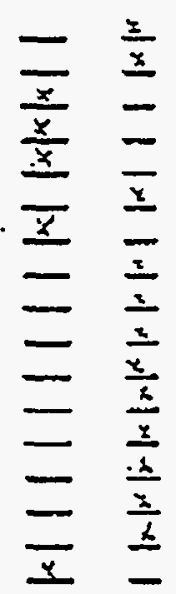

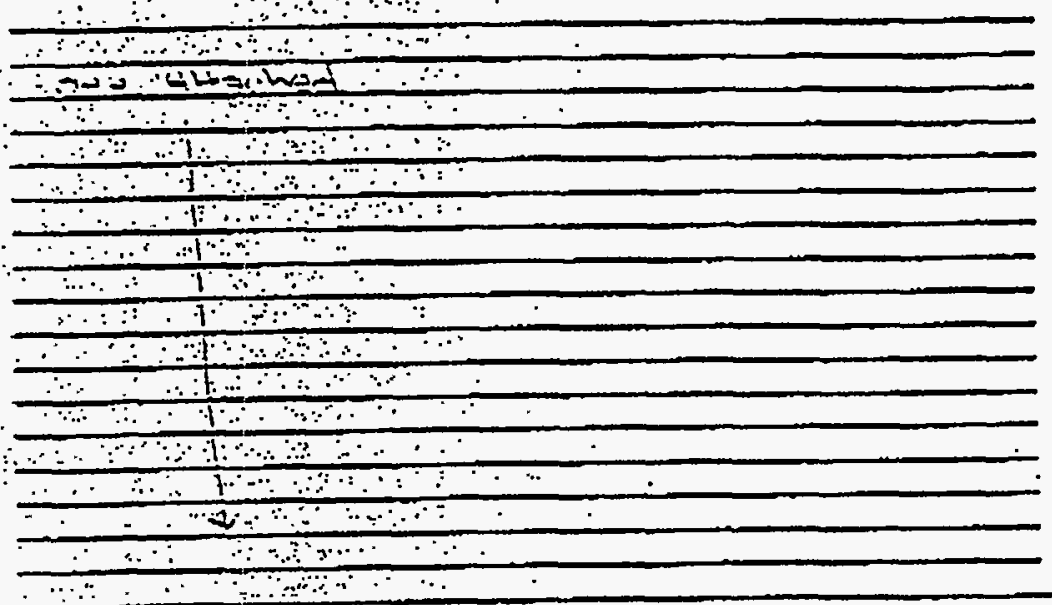

c.

\section{CATESCRY EYaLUATOOH CQITERT}

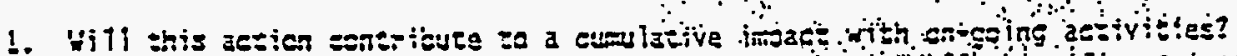

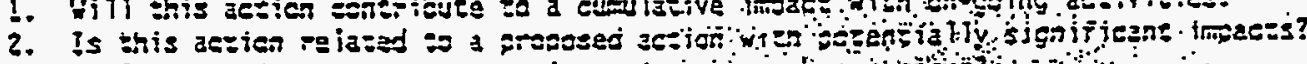

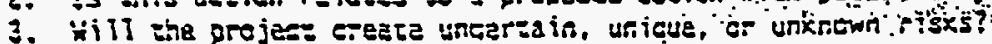

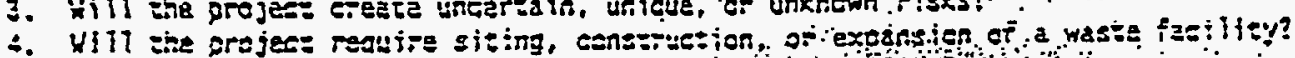

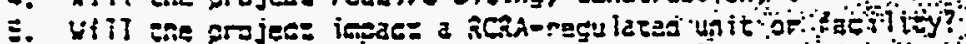

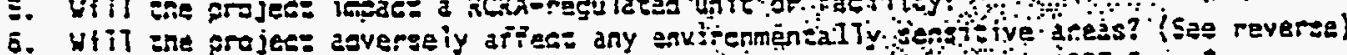

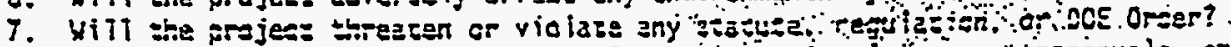

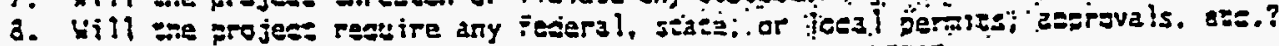

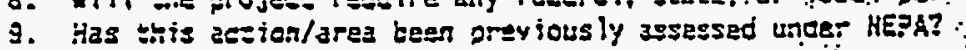

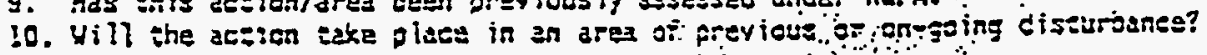

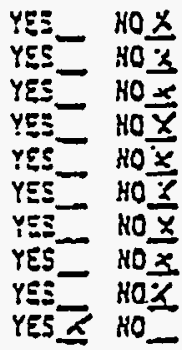

D. COE CONTRACTOR MEPR CATESORY RECOHMEHOATION: REFERENCE:

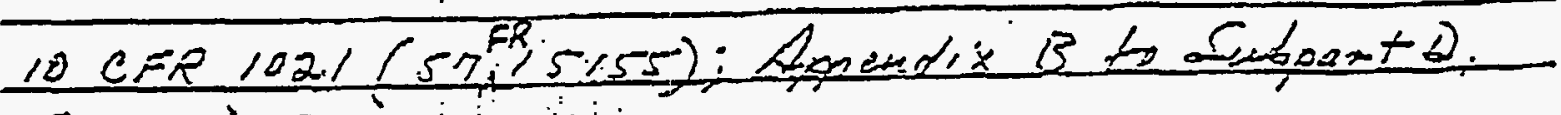

$$
\begin{aligned}
& \text { Pertes is } 23.6
\end{aligned}
$$

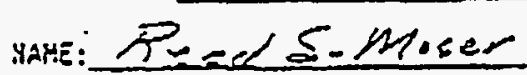

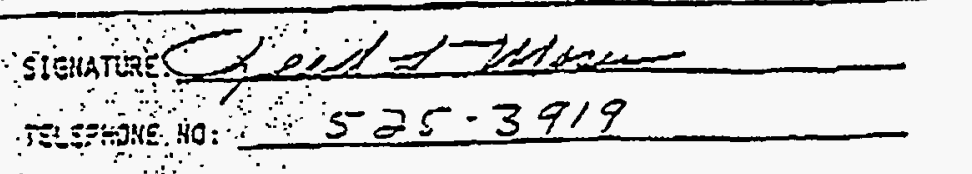$$
\text { ofie: } \quad 7 / 21 / 92
$$

D-8 


\section{CATESORICAL EXCLUSION FOR \\ RADIATION HEASUREHENTS LABORATORY \\ IDAHO NATIONAL ENEINEERINE LABORATORY (INEL)}

Prooosed Action: Radiation-Measurements Laboratory (RML), Taboratory operations

Location of Action: Test Reactor Area (TRA), Idaho National Enginearing - Laboratory (INEL), Idaho

Pronosed BV: Energy Technology Division, DOE-ID

Descriation of Proposed Action:

The proposed action entails laboratory operations and bench-scale research and development conducted on a routine basis at the Radiation Measurements Laboratory (RML). Fundamental activities inciuding the following: 1) Determination of radionuclide content on verious sample media, using highresolution ganura-ray spectroscopy; 2) Design, fabrication, and repair of electronic instrumentation; inciuding development and testing of systems used for non-invasive assay; 3) Computer software development; and, 4) Applied research in radiation physics which includes support of fuel and target development for the Modular High Temperature Gas Reactor, evaluation and applications testing of instrumentation to support waste managenent and remediation efforts; and development of advenced concepts for the office of Arms Control.

The following impacts are involved with RML operations: 1) Solid waste is generated in the form of waste paper and alkaline betteries; 2) Radioactive waste is generated in Small amounts in.both the liquid and solid form, primarily from researci and development activities; 3) Hazardous waste is generated in very small quantities from chemical use or disposal of outdated chemicals; 4) Chemical storage and: use is involved in the handling of chemicals used for electronic cleaning and soldering, film development and various research and development. activities; and, 5) Radiation exposure couTd be involved due to the handing of sealed sources, or due to the requirements that a job be performed in a radiation: area... As low as reasonably achievable goals are establisined and maintained to minimize personnel exposure.

\section{Categorical Exclusion to be Aopilied:}

DOE NEPA Regulations, 10 CFR I021 at 57 FR 15155, Appendix $B$ to Subpart D, as follows:

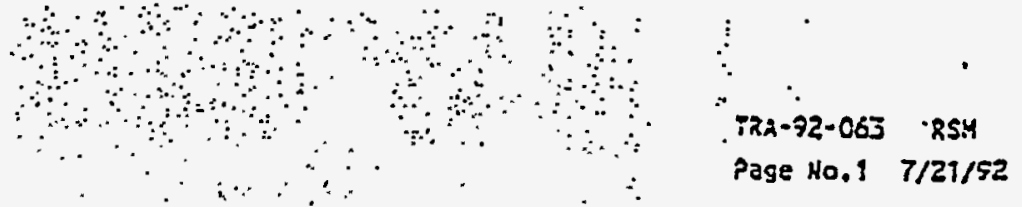


- Section 83.6: "Incoor bench-scale resaarch projects anc conventionai laboratory copertions: (for example, praparation of chemicil standards and sample analysis. "itining existing iaborstory iacilities."

The proposed action woula" noti lijtirecten a violation of applicable stetutory, regulatory, or permit requirements for environmental, safety, and health, including requirement sof pos Orciers; 2) require siting and consiruction or major expansion of waste storage, disposal, recovery, or treatment facilities; 3) disturb hiajercous. Substances, poilutants, contaminants, or CERCLA-exciluded pe froleum ano natural gas products tnat pre-exist in the environment suchingt there; would je uncontrolled or unpermitted releases; or 4) adversely atiect enviromentally sensitive resourcas.

Determination:

I have determined that the proposed action for the Radiation Mecsuraments Laboratory at the INE! meets the trequirements for the $C_{x}$ reterenced above. Therefore, I have determined that the proposed action is categoricaliy excluded from furting NEPA reyiewsind cocumentetion.

Approval:

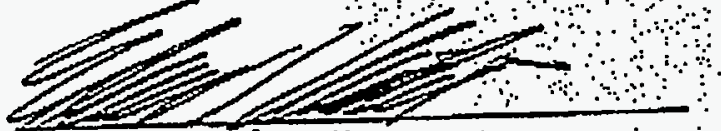

Data:

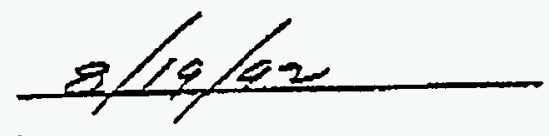

A. A. Pitrolo, Manager:

DOE Idaho Field OtTicá

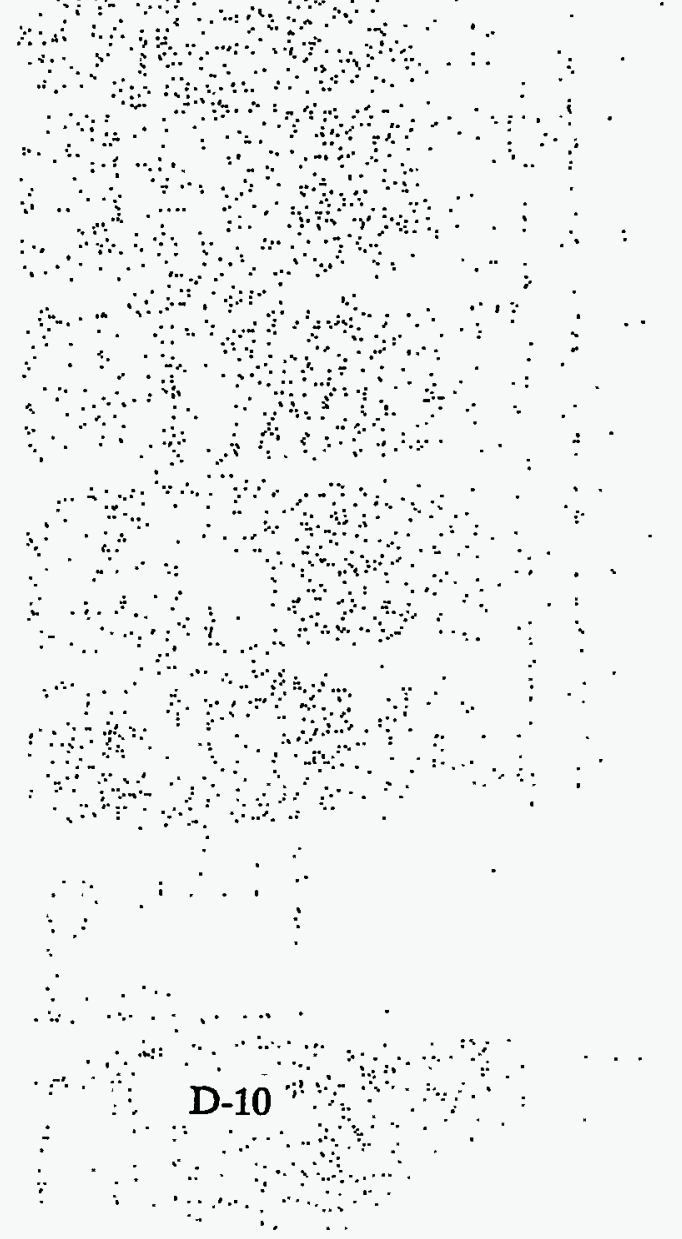

